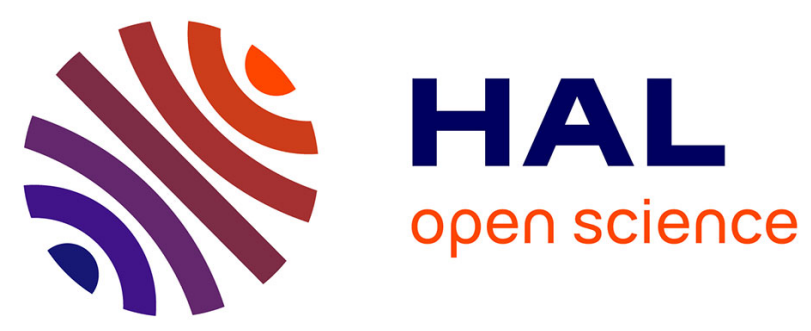

\title{
Determination of the refractory enrichment factor of the bulk silicate Earth from metal-silicate experiments on rare Earth elements
}

P. Faure, M. Boyet, Mohamed Ali M.A. Bouhifd, Geeth Manthilake, T. Hammouda, J.-L. Devidal

\section{To cite this version:}

P. Faure, M. Boyet, Mohamed Ali M.A. Bouhifd, Geeth Manthilake, T. Hammouda, et al.. Determination of the refractory enrichment factor of the bulk silicate Earth from metal-silicate experiments on rare Earth elements. Earth and Planetary Science Letters, 2021, pp.116644. 10.1016/j.epsl.2020.116644 . hal-03004013

\section{HAL Id: hal-03004013 \\ https://hal.uca.fr/hal-03004013}

Submitted on 13 Nov 2020

HAL is a multi-disciplinary open access archive for the deposit and dissemination of scientific research documents, whether they are published or not. The documents may come from teaching and research institutions in France or abroad, or from public or private research centers.
L'archive ouverte pluridisciplinaire HAL, est destinée au dépôt et à la diffusion de documents scientifiques de niveau recherche, publiés ou non, émanant des établissements d'enseignement et de recherche français ou étrangers, des laboratoires publics ou privés.

$$
\text { Copyright }
$$




\title{
Determination of the refractory enrichment factor of the bulk silicate Earth from
} metal-silicate experiments on Rare Earth Elements

\author{
P. Faure $^{1}$, M. Boyet ${ }^{1 *}$, M.A. Bouhifd ${ }^{1}$, G. Manthilake ${ }^{1}$, \\ T. Hammouda ${ }^{1}$ and J.-L. Devidal ${ }^{1}$ \\ ${ }^{1}$ Laboratoire Magmas et Volcans, Université Clermont Auvergne, CNRS UMR 6524, \\ OPGC-IRD, F-63000 Clermont-Ferrand, France \\ *Corresponding authors: maud.boyet@uca.fr
}

\section{Abstract}

This study investigates the partitioning of rare earth elements (REE) from La to Gd between molten metal and silicate to evaluate potential fractionation occurring during core-mantle differentiation. We report molten metal-silicate liquid partition coefficients from 24 multi-anvil experiments, extending the range of pressure, previously ranging from 1 to $8 \mathrm{GPa}$, up to $14 \mathrm{GPa}$. Experiments were performed at temperatures of between 2300 and $2560 \mathrm{~K}$, and for oxygen fugacities ranging from the IW (Iron-Wüstite buffer) to IW -4. Metal-silicate partition coefficients for the studied REE vary with the oxygen fugacity and $\mathrm{S}$ concentration in the metallic phase of the system. These elements were all lithophile during the Earth's accretion. By compiling all existing data on molten metal-silicate liquid partitioning, REE partitioning between the mantle and core during the Earth's accretion can be determined for a wide range of $\mathrm{P}, \mathrm{T}$ and $f_{\mathrm{o}_{2}}$ conditions representing the early evolution of planetary bodies from planetesimals to planets. REE concentrations of the bulk silicate Earth (BSE) are calculated from accretion scenarios using varying proportions and compositions of chondritic building blocks. The models 
26 selected are those that reproduce the Earth's nucleosynthetic isotope signature and the $27 \mathrm{Ni} / \mathrm{Co}, \mathrm{Th} / \mathrm{U}$ and $\mathrm{Nb} / \mathrm{Ta}$ ratios of the BSE. The BSE refractory element enrichment 28 factor determined from REE data is equal to 2.88 (relative to CI chondrites). This 29 calculation takes into account the depletion in volatile elements in the Earth compared 30 to chondrites. This new estimate is in good agreement with previous determinations 31 based on analysis of the upper mantle rocks, which supports the idea of a chemically 32 homogeneous mantle. We also confirm that the formation of the core, with or without 33 segregation of a sulfide phase, does not fractionate $\mathrm{Sm} / \mathrm{Nd}$ and cannot be responsible for 34 the ${ }^{142} \mathrm{Nd}$ excess measured in modern terrestrial samples relative to chondrites. 


\section{Introduction}

The planets of our Solar System result from the accretion of smaller objects including differentiated protoplanetary bodies and primitive objects formed in the early Sun's protoplanetary disk. The bulk chemical compositions of differentiated objects, which are composed of a metallic core surrounded by a silicate reservoir, are difficult to estimate because we do not have access to all the different reservoirs. Core-mantle differentiation processes concentrate chemical elements in the different reservoirs according to their partition coefficients. Siderophile elements are preferentially drawn into the metallic core whereas lithophile elements remain in the silicate portion. Chondrites, which escaped planetary differentiation, are commonly used as a reference for elements characterized by a high condensation temperature called refractory elements. Unlike volatile elements, they must not have been partially lost during the accretion stage. Then planetary bodies should retain chondritic ratios of refractory lithophile elements (RLE) in their silicate parts. Ratios of two elements characterized by a high condensation temperature (e.g. $\mathrm{Ca}, \mathrm{Al}$, rare earth elements) are similar in the different chondrite groups (Wasson and Kallemeyn, 1988). This observation forms the basis for many geochemical models used for reconstructing the composition of the bulk silicate Earth (BSE). Proposed BSE compositions have chondritic RLE ratios, and the absolute concentrations in the BSE for these elements are commonly expressed in the literature using the enrichment factor (EF), which is the BSE to CI concentration ratio $\left(\mathrm{EF}=[\mathrm{RLE}]_{\mathrm{BSE}} /[\mathrm{RLE}]_{\mathrm{CI}}\right)$. This enrichment factor is usually determined from the concentrations measured for highly refractory elements (e.g. Al, Ti) in the most fertile upper mantle rocks. Once determined, it is applied to all RLE to calculate the BSE composition. Enrichment factors are in the range of 1.7 to 2.8 in the literature 
explaining the differences in published BSE compositions (Lyubetskaya and Korenaga, 2007; McDonough and Sun, 1995; Palme and O’Neill, 2014). Concentrations in heatproducing elements vary by $\sim 20 \%$ in the different BSE models with important implications on the geodynamics and habitability of Earth (Jellinek and Jackson 2015).

The absence of RLE fractionation during the early phase of the Earth's evolution has been challenged, due to the presence of small ${ }^{142} \mathrm{Nd} /{ }^{144} \mathrm{Nd}$ excesses in modern terrestrial samples relative to chondrites (up to 30 parts per million in the ${ }^{142} \mathrm{Nd} /{ }^{144} \mathrm{Nd}$ ratio depending of the chondrite group; Boyet and Carlson, 2005). Since ${ }^{142} \mathrm{Nd}$ is a radiogenic isotope partly produced by the decay of ${ }^{146} \mathrm{Sm} \quad\left(\mathrm{T}_{1 / 2}=103 \mathrm{Ma}\right)$, a very early differentiation event of the silicate Earth had been proposed to explain this offset (Boyet and Carlson, 2005). Variation in the ${ }^{142} \mathrm{Nd} /{ }^{144} \mathrm{Nd}$ ratio measured between the different groups of chondrites reflects nucleosynthetic heterogeneities in the protoplanetary disk during the accretion stage (Boyet et al., 2018). However, variations in mass-independent stable isotope ratios for $\mathrm{Nd}\left({ }^{145} \mathrm{Nd} /{ }^{144} \mathrm{Nd},{ }^{148} \mathrm{Nd} /{ }^{144} \mathrm{Nd}\right.$ and $\left.{ }^{150} \mathrm{Nd} /{ }^{144} \mathrm{Nd}\right)$ are too small to be clearly resolved, with the exception of carbonaceous chondrites (Saji et al., 2016). The smallest difference in ${ }^{142} \mathrm{Nd}$ between chondrite and terrestrial samples is for the enstatite chondrite group (average value $-10 \mathrm{ppm}$, Boyet et al., 2018). Enstatite chondrites (EC) display nucleosynthetic isotope signature similar to BSE for a large number of isotope systematics suggesting that they represent a large fraction of the material accreted to form the Earth (e.g. Dauphas 2017). Because the analytical precision is not sufficient to detect significant variations in other $\mathrm{Nd}$ isotope ratios in EC relative to the terrestrial reference, a radiogenic origin of the ${ }^{142} \mathrm{Nd}$ excess measured in modern terrestrial samples cannot be totally disproved. In this case the small excess 
83 of ${ }^{142} \mathrm{Nd}$ in modern terrestrial samples relative to chondrites could be the result of

$84 \mathrm{Sm} / \mathrm{Nd}$ fractionation produced during the lifetime of the parent isotope, i.e. during the 85 first 500 Ma of Solar System history.

The Earth's core was proposed by Andreasen et al. (2008) as a potential enriched reservoir (early-formed low $\mathrm{Sm} / \mathrm{Nd}$ reservoir characterized by deficit in ${ }^{142} \mathrm{Nd}$ ), even though no REE partition coefficients were available then for core-forming conditions. While experimental data suggest that $\mathrm{Sm}$ and $\mathrm{Nd}$ remain lithophile and behave in a similar fashion during liquid metal - liquid silicate partitioning (Bouhifd et al., 2015), it has been proposed that the addition of a significant amount of $\mathrm{S}$ into the core would fractionate $\mathrm{Sm}$ and $\mathrm{Nd}$ enough to explain the small ${ }^{142} \mathrm{Nd}$ excess in modern terrestrial samples relative to chondrites (Wohlers and Wood, 2015). A small number of recent experiments performed at higher temperature $\left(2100^{\circ} \mathrm{C}\right)$, more compatible with core formation conditions, seems to rebut elemental fractionation between $\mathrm{Sm}$ and $\mathrm{Nd}$ in a sulfur-rich environment (Wohlers and Wood, 2017). To further constrain the behaviour of REE during core-mantle differentiation processes, we report molten metal-silicate liquid partition coefficients (D) determined from 24 multi-anvil experiments. We extended the range of pressure to $14 \mathrm{GPa}$, as previous measurements had only been carried out between 1.5 and $8 \mathrm{GPa}$. Experiments were performed from 2300 to $2560 \mathrm{~K}$,

102 and for oxygen fugacity conditions ranging from IW (Iron-Wüstite buffer) to IW-4.

103 Partition coefficients were determined for REE from La to Gd in a liquid metal-liquid 104 silicate system with various amounts of S. Our new data set, combined with all existing 105 experimental results, give a consistent parameterisation of the behaviour of these 106 elements during magma ocean episodes for planetary bodies of different sizes 
107 (planetesimals to planets) and for compositions representing the diversity found in the 108 inner Solar System.

\section{2. Experimental methods}

\section{$111 \quad$ 2.1. Starting materials}

112 The starting material for the silicate consisted of a natural equilibrated EC from the EL6 113 subgroup (Hvittis, composition given by Rubin, 1983). Once finely ground, the powder

114 was doped with the studied elements, at a level ranging from $1500 \mathrm{ppm}$ to $1 \mathrm{wt} \%$ per

115 REE. Since the field of application of Henry's law is not well defined for REE, we 116 decided to split the studied REE into two different doping solutions, synthesized from 117 AAS standard solutions, in order to minimize the amount of trace elements in the 118 starting materials. Type A solution contained La, Ce, Pr, Nd and Sm, while type B 119 solution contained $\mathrm{Nd}, \mathrm{Sm}, \mathrm{Eu}$ and $\mathrm{Gd}$. For sulfur-rich experiments, a type C solution 120 containing all 7 REE from La to Gd at a level of 1500 ppm each was synthesized. All 121 solutions contained $\mathrm{Nd}$ and $\mathrm{Sm}$ in order to compare our experiments with previous 122 studies (Bouhifd et al., 2015; Wohlers and Wood, 2017).

124 Various amounts of Fe-rich alloys (in the Fe-Ni-Si-S system) were then added in a 125 weight proportion of 50:50. Control of the $f_{\mathrm{O}_{2}}$ between IW to IW-4 was obtained by 126 addition of metallic Si to the starting material, resulting in the reduction of the $\mathrm{FeO}$ 127 present in the silicate phase from about $20 \mathrm{wt} \%$ to $\sim 0.2 \mathrm{wt} \%$ in some run-products. Each 128 composition was mixed and ground in ethanol, before being dried and stored in a 129 vacuum sealed dessicator for at least $48 \mathrm{~h}$. 


\subsection{High-pressure and high-temperature syntheses}

132 High-pressure and high-temperature experiments were carried out using the 1000-ton

133 and 1500-ton multi-anvil apparatuses installed at the French National High-Pressure

134 facility of Laboratoire Magmas et Volcans (LMV) in Clermont-Ferrand. Experimental

135 conditions are summarised in Table 1, based on pressure calibrations similar to those

136 already described in Boujibar et al., (2014) and Hammouda (2003). The pressure

137 assemblies consisted of Cr-doped $\mathrm{MgO}$ octahedra, 18 or $14 \mathrm{~mm}$ edge length, containing

138 a stepped graphite or $\mathrm{LaCrO}_{3}$ heater, respectively. Octahedra were compressed using 32

$139 \mathrm{~mm}$ tungsten carbide anvils with truncation edge lengths of 11 and $8 \mathrm{~mm}$ (with 18 and

$14014 \mathrm{~mm}$ octahedra, respectively) and pyrophyllite gaskets. The samples were contained

141 either in graphite for $6 \mathrm{GPa}$ experiments or in $\mathrm{MgO}$ single crystal capsules for $14 \mathrm{GPa}$

142 experiments. The assembled octahedra were dried in an oven at $500 \mathrm{~K}$ overnight before

143 each experiment. The samples were first compressed to the target pressure at room

144 temperature and then heated to the desired temperature (between 2300 and $2560 \mathrm{~K}$ ) for

145 durations of 2 to $4 \mathrm{~min}$. These durations are sufficient to achieve equilibrium between

146 silicate melt and metallic liquid (e.g. Boujibar et al., 2014; Faure et al., 2020; Siebert et

147 al., 2011) while preventing excessive reaction between the capsule and the silicate or

148 metallic phases. Textural and chemical evidences (uniformed quenched silicate melts,

149 well-formed metal blobs, chemically homogeneous metallic and silicate phases)

150 confirmed that equilibrium was achieved in the sample. Temperatures were monitored

151 with a thin axial $\mathrm{W}_{5} \mathrm{Re} / \mathrm{W}_{26} \mathrm{Re}$ thermocouple whose junction was in direct contact with

152 the top of the capsule. In the event that the thermocouple was lost, the temperature was

153 determined using the power/temperature relation determined in previous experiments.

154 The pressure and temperature uncertainties are estimated to be $\pm 1 \mathrm{GPa}$ and $\pm 100 \mathrm{~K}$ 
respectively, since no pressure correction was made for the emf of the thermocouple (e.g. Li et al., 2003). The samples were quenched by shutting off the power, which resulted in a quench rate of approximately $800 \mathrm{~K} / \mathrm{s}$. The samples were then decompressed over a period of about $12 \mathrm{~h}$. After the experiment, the run-product was mounted in epoxy, polished and carbon coated for the chemical analyses.

\subsection{Electron Microprobe}

Major and minor elements in the metal and silicate phases were analyzed using the LMV CAMECA SX100 electron microprobe using a $20 \mathrm{kV}$ accelerating voltage. Major elements analyses in the silicate phase were performed at $50 \mathrm{nA}$ with a 5-20 $\mu \mathrm{m}$ defocused beam, counting times on the peak ranging from 5 to 80 seconds depending on element concentrations and detection limit requirements. The standards for silicates were natural minerals and synthetic oxides $(\mathrm{Si}, \mathrm{Ca}$ : wollastonite; $\mathrm{Mg}$ : forsterite; $\mathrm{Al}$ : $\mathrm{Al}_{2} \mathrm{O}_{3} ; \mathrm{Fe}$ : fayalite; Na: albite; K: orthoclase; Ti, Mn: $\mathrm{MnTiO}_{3} ; \mathrm{Cr}: \mathrm{Cr}_{2} \mathrm{O}_{3} ; \mathrm{Ni}: \mathrm{NiO}$ ). For metallic and sulfide phase analyses, we used a defocused beam $(10-20 \mu \mathrm{m})$, beam currents of $15 \mathrm{nA}$ for the major elements $(\mathrm{Fe}, \mathrm{Ni}, \mathrm{S}$ and $\mathrm{Si}$ ) and $150 \mathrm{nA}$ for the trace elements, and counting times on the peak ranging from 5 to $60 \mathrm{~s}$. Standards were pyrite for $\mathrm{Fe}$ and $\mathrm{S}$ in sulfides, and pure metal (Fe, Mn, $\mathrm{Si}, \mathrm{Mg}, \mathrm{Ni}, \mathrm{Cr}$ ) for metallic alloys. For samples embedded in graphite capsules, the carbon content in Fe-alloys was estimated from the deviation of the analyses totals from $100 \%$.

\subsection{Laser Ablation ICP-MS}

Trace element concentrations were determined using the LMV Elements XR laserinduced coupled plasma-mass spectrometer (LA ICP-MS) coupled with a $193 \mathrm{~nm} \mathrm{ArF}$ 
excimer type laser (Resonetics M-50). The laser was fired at selected sample regions at

180 a repetition rate of 2 to $4 \mathrm{~Hz}$ with $4 \mathrm{~mJ}$ output energy beam, with a spot size diameter of

$181 \quad 15-44 \mu \mathrm{m}$ in the silicate, and $80-130 \mu \mathrm{m}$ in the metal. Ablation duration lasted usually

182 around $80 \mathrm{~s}$ and was done in a pure He atmosphere. Reference material glasses NIST

183 SRM 610, NIST 612 and BCR2-G were used for external calibration (Gagnon et al.,

184 2008), and ${ }^{29} \mathrm{Si},{ }^{57} \mathrm{Fe}$ and ${ }^{60} \mathrm{Ni}$ were used as internal calibrators. All data were processed

185 using the GLITTER software package (Achterberg et al., 2001). Ca signal was

186 monitored during metal analyses and Fe and Ni signals during silicate analyses. Any

187 sudden variation in their content was considered as indicative of phase contamination

188 (metal contamination during the silicate phase analysis, or vice versa) and the

189 corresponding analyses were rejected.

190

\subsection{Oxygen fugacity determination}

192 Oxygen fugacity was calculated using the $\mathrm{Fe}$ and $\mathrm{FeO}$ contents of the metal and silicate

193 quenched phases, using the equilibrium reaction:

$194 \mathrm{Fe}^{\text {metal }}+1 / 2 \mathrm{O}_{2} \leftrightarrow \mathrm{FeO}^{\text {silicate }}$

195 The $f_{\mathrm{O}_{2}}$ was estimated relative to the Iron-Wüstite buffer (IW) from the activities of Fe

196 and $\mathrm{FeO}$ in the metal and silicate following the equation:

$197 \log f_{\mathrm{O}_{2}}(\Delta \mathrm{IW})=2 \times \log \left(\frac{a_{F e O}^{s i l}}{a_{F e}^{m e t}}\right)$

198 where $a_{F e O}^{\text {sil }}=\gamma_{F e O}^{\text {sil }} \times X_{F e O}^{\text {sil }}$ and $a_{F e}^{m e t}=\gamma_{F e}^{m e t} \times X_{F e}^{m e t}$ represent the activity of FeO in the

199 silicate liquid and $\mathrm{Fe}$ in the metal phase, respectively. $X_{F e}^{m e t}$ and $X_{F e O}^{s i l}$ are the molar

200 fractions of $\mathrm{Fe}$ in the metallic phase and $\mathrm{FeO}$ in the silicate liquid. $\gamma_{\mathrm{FeO}}^{\text {sil }}$ and 
$\gamma_{F e}^{m e t}$ represent the activity coefficient of $\mathrm{FeO}$ in the silicate liquid, and the activity of $\mathrm{Fe}$

202 in the metallic phase, respectively.

203 The Fe activity coefficient in Fe-rich alloys was calculated from the formula of Ma 204 (2001), using the interaction parameters $\varepsilon$ provided Wade and Wood (2005) and the 205 activity calculator (http://www.earth.ox.ac.uk/ expet/metalact/) provided by the 206 University of Oxford.

207 We used the average gamma value derived from studies at 1 bar by O'Neill and Eggins 208 (2002) for several melt compositions in the $\mathrm{CaO}-\mathrm{MgO}-\mathrm{Al}_{2} \mathrm{O}_{3}-\mathrm{SiO}_{2}$ system, and by 209 Holzheid et al. (1997) for melts in the anorthite-diopside system and komatiitic basalt, 210 assuming no pressure effect on the activity coefficients in silicate melts (Toplis, 2004).

\section{Results}

\section{3.1. Phase assemblages and compositions}

214 Typical run products consisted of quenched silicate melts and liquid metal blobs (Figure 215 1). Measured chemical compositions of the quenched silicate and metallic melts are 216 reported in Appendix A. The run-product microstructures show that both phases became 217 fully molten during the high pressure and high temperature experiments. The metallic 218 phase generally forms a large "core" located at the center or to one side of the capsule 219 or, less frequently, large drops distributed throughout the sample. In some cases, 220 dendritic microstructures are observed in the silicate, requiring a defocused beam for 221 chemical analyses to average the heterogeneous quenched textures. Several criteria are used to demonstrate the thermodynamic equilibrium of these experimental samples: (i) multiple analyses in the silicate phase show that it is homogeneous with no evidence of 
chemical zoning, and (ii) all metal blobs embedded in the silicate matrix have identical composition within uncertainties.

In the present study we also tested the effect of the nature of the capsule (graphite vs. $\mathrm{MgO}$ single crystal) on REE partitioning. Using graphite capsules, analytical totals for the metallic phases indicate some amount of $\mathrm{C}$ dissolved in the metal (from 0.21 to $4.99 \mathrm{wt} \%$, see Appendix A1). More details about the dissolution of C into the metallic phases are reported in Appendix A2. On the other hand, the $\mathrm{MgO}$ single crystal capsule tends to saturate the silicate phase in $\mathrm{MgO}$, leading to the formation of olivine quenched crystals instead of enstatite in these samples. Previous studies based on multi-anvil and 234 piston-cylinder experiments (Bouhifd et al., 2015; Wohlers and Wood, 2017) showed that these interactions do not have a significant effect on the partitioning of REE. In addition, we observed no noticeable difference in REE molten metal-silicate liquid partition coefficients between $14 \mathrm{GPa}(\mathrm{MgO}$ single crystal capsule) and $6 \mathrm{GPa}$ (graphite

238 capsule) experiments for a similar range of temperature, $f_{\mathrm{O}_{2}}$ and chemical composition, 239 showing no significant impact of the nature of the capsule or pressure in our experiments (Appendix B).

\subsection{Experimental partition coefficients}

243 Overall, 24 experiments were performed, resulting in 24 new partition coefficients for

$244 \mathrm{Sm}$ and $\mathrm{Nd}$ and 15 for La, Ce, Pr, Eu and Gd (Table 1). Molten metal - silicate liquid 245 partitioning are always low, ranging from $10^{-3}$ to $10^{-6}$, in agreement with results 246 obtained in previous studies for experiments performed at similar conditions (see 247 Appendix C). The two main parameters influencing liquid metal - liquid silicate 
248 partition coefficients are the oxygen fugacity and the sulfur content of the metallic 249 phase. Changing the oxygen fugacity conditions from IW-4 to IW-1 leads to a decrease 250 in the partition coefficient by two to three orders of magnitude (Figure 2 and Appendix 251 D.1). On the other hand, the transition from pure Fe metal to pure FeS increases the 252 partition coefficient of all studied REE by up to three orders of magnitude (Figure 3 and 253 Appendix D.2).

255 Europium behaves slightly differently to other studied REE in our experimental 256 conditions (Figures 2-4). Around the Iron-Wüstite buffer, more than $50 \%$ Eu is divalent 257 in a basaltic melt (Burnham et al., 2015). Thus, in the redox conditions of the present 258 study, $\mathrm{Eu}$ is mainly in a +2 valence state. $\mathrm{Eu}^{2+}$ is more stable in a sulfide phase than all 259 the other trivalent REE, as shown in all the FeS-bearing experiments in this study 260 (Figure 4). In all sulfur-rich samples, the sulfide phase is enriched in Eu, leading to a 261 mean $\mathrm{D}_{\mathrm{Eu}} 2.5$ times higher than the partition coefficients for the other REE. Values from 262 the literature are also plotted in Figure 4. Results obtained from experiments performed 263 in evacuated silica tubes at temperatures of between 1200 and $1400{ }^{\circ} \mathrm{C}$ (Ingrao et al., 264 2019; Lodders, 1996) are in agreement with our results. These similarities strongly 265 suggest that pressure and temperature have a negligible effect on molten Fe-rich alloy 266 silicate liquid partitioning of the studied REE ( $\left.D_{\mathrm{REE}}\right)$. That $D_{\mathrm{REE}}$ is little dependent on 267 temperature can be can be shown by the fact that the free energy of the exchange 268 reactions for REE are not sensitive to the variation of the temperature in the likely range during core formation (details are reported in Appendix D.3). 
By including experiments from previous studies, it is also possible to analyze the impact

272 of the nature of the silicate phase on the behavior of the studied REE. The NBO/T

273 (Non-Bridging Oxygen per Tetrahedral cations) value is an indicator of melt

274 polymerization, with zero corresponding to a completely polymerized melt $\left(\mathrm{SiO}_{2} \mathrm{melt}\right)$

275 and a value of 4 corresponding to a completely depolymerized melt $\left(\mathrm{Mg}_{2} \mathrm{SiO}_{4}\right.$ melt). For

276 roughly similar experimental conditions and metallic compositions, and for a large

277 difference in silicate composition (NBO/T from 0.5 to 3.7, see Appendix A and C), the

$278 D_{\text {REE }}$ coefficients are similar within the analytical uncertainties. Furthermore, besides

$279 \mathrm{FeO}$ that is directly related to the oxygen fugacity of experiments, we find no significant

280 impact of any of the major oxides that compose the silicate phase on the partition

281 coefficient of the studied REE, for the available dataset. Therefore, data suggest that the

282 silicate melt composition has no significant influence on the REE metal-silicate 283 partition coefficients.

284

285 3.3. Parameterisation of the results

286 Partitioning of an element between metal and silicate phases can be considered as an 287 exchange reaction involving $\mathrm{Fe}, \mathrm{FeO}$ and the oxidized and reduced components of 288 element $\mathrm{M}$, of valence $n$ :

$289 M O_{n / 2}+\frac{n}{2} \mathrm{Fe}=\frac{n}{2} \mathrm{FeO}+\mathrm{M}$

290 By considering the equilibrium for this exchange reaction, it is possible to write the

291 following relationship between $\log \left(D_{\mathrm{M}}\right)$ and $\log \left(\mathrm{f}_{2}\right)$ (Righter et al., 2010):

$292 \log \left(D_{M}\right)=a \log \left(f o_{2}\right)+b \frac{1}{T}+c \frac{P}{T}+d \log \left(1-X_{S \text { metal }}\right)+e$ 
293 The $a, b, c$, and $e$ terms relate to valence $n\left(a=-\frac{n}{4}\right)$, enthalpy $\left(\frac{\Delta H^{\circ}}{R T}\right)$, volume $\left(\frac{P \Delta V^{\circ}}{R T}\right)$, 294 and entropy $\left(\frac{\Delta S^{\circ}}{R}\right)$, respectively. The empirical term $d$ takes into account the effect of 295 sulfur in a metallic liquid ( $\mathrm{X}_{\text {Smetal }}$ is the wt.\% of S into the metallic phase), as discussed 296 previously.

298 In order to refine the values of $a$ and $d$ for $\mathrm{La}, \mathrm{Ce}, \mathrm{Nd}, \mathrm{Sm}, \mathrm{Eu}$, and $\mathrm{Gd}$, we used all 299 existing data sets for which the partitioning behavior, phase compositions and 300 experimental conditions (temperature, pressure, oxygen fugacity) had been accurately 301 determined. We considered solid silicate for experiments performed at $T<$ melting 302 temperature of the silicate phase (liquidus). The references as well as the conditions (P, $303 \mathrm{~T}, f_{\mathrm{O}_{2}}$ ) available for each experiment are listed in Appendices A and C. We used a 304 multiple linear regression (approach used by Bouhifd et al., 2015; Faure et al., 2020; 305 Righter et al., 2010) for each element of interest. For every regression, the robustness of 306 each overall model significance was determined using a Fisher-Snedecor test, and a 307 Student test was run to assess the significance of every variable. Results of the two308 variable parameterisation for $\mathrm{La}, \mathrm{Ce}, \mathrm{Pr}, \mathrm{Nd}, \mathrm{Sm}, \mathrm{Eu}$ and $\mathrm{Gd}$ are summarized in Table 2 309 with their respective standard deviations and determination coefficients. The p-values 310 determined for each variable are also reported. As seen above, only $a$ and $d$ are relevant 311 to REE partitioning behavior. The parameters $b$ and $c$, corresponding respectively to the 312 effect of $\mathrm{T}$ and $\mathrm{P}$ are found here of no statistical significance, and are therefore set equal 313 to 0 . This result reflects the negligible impact that $\mathrm{T}$ and $\mathrm{P}$ have on $\mathrm{D}_{\mathrm{REE}}$ (Appendix $\mathrm{B}$ ), 314 in comparison to the effect displayed by $\mathrm{X}_{\text {Smetal }}$ and $f_{\mathrm{o}_{2}}$, within a dataset containing 315 experiments performed up to $14 \mathrm{GPa}$ and $2560 \mathrm{~K}$. While this observation is in 316 agreement and validate previous studies based on a smaller range of $\mathrm{P}$ and $\mathrm{T}$ (Bouhifd et 
al., 2015; Wohlers and Wood, 2017), a dependence on pressure or temperature might be resolved when data obtained from higher pressure experiments will be collected.

320 The value of parameter $a$ being proportional to the valence of one element (equations 5 321 and 6), the parameterisations proposed here are consistent with all REE being in a +3 322 valence state within the studied range of oxygen fugacity conditions, with the exception 323 of $\mathrm{Eu}$, which is essentially +2 below the IW buffer. In an S-free system, an oxygen 324 fugacity from IW-5 to IW-2 will lead to a decrease in $\mathrm{D}_{\mathrm{Nd}}$ from $2.32 \times 10^{-3}$ to $3.76 \times 10^{-5}$ 325 and a decrease in $\mathrm{D}_{\mathrm{Eu}}$ from $3.71 \times 10^{-4}$ to $2.34 \times 10^{-5}$ (Figure 2). The effect of the sulfur 326 content of the metal is also noticeable in our parameterisation, leading to an increase of 327 all REE partition coefficients by about three orders of magnitude when the S content in 328 the metallic phase increases from 0 to $\sim 35 \mathrm{wt} \%$ at constant oxygen fugacity. For 329 example, at IW-2, $\mathrm{D}_{\mathrm{Eu}}$ increases from $2.34 \times 10^{-5}$ to $2.45 \times 10^{-2}$ and $\mathrm{D}_{\mathrm{Nd}}$ increases from $3303.31 \times 10^{-5}$ to $2.56 \times 10^{-2}$ (Figure 3 ). No noticeable difference is found between Eu and the 331 other REE with respect to the effect of the sulfur content in metal. In the discussion, we 332 will use parameterisations obtained in the range of conditions of the available dataset, in order to establish the partitioning of REE in the conditions of Earth's core formation.

\section{Discussion}

\section{4.1. Absence of Sm-Nd fractionation during planetary core formation}

337 Previous high pressure - high temperature experiments led to different conclusions 338 concerning the role of core formation on the $\mathrm{Sm} / \mathrm{Nd}$ ratio of the BSE. Elemental 339 fractionation between $\mathrm{Sm}$ and $\mathrm{Nd}$ was reported from sulfide-silicate partitioning data in 340 experiments performed at $1.5 \mathrm{GPa}$ and temperatures between 1400 and $1650^{\circ} \mathrm{C}$ 
341 (Wohlers and Wood, 2015). However, when both phases are molten, this fractionation is

342 no longer observed. This is shown in our study and from published high pressure - high

343 temperature experiment datasets (Figure 5, Bouhifd et al., 2015; Wohlers and Wood, 344 2017). Sulfide-silicate and metal-silicate partition coefficients for Sm and Nd vary with 345 two parameters: $f_{\mathrm{o}_{2}}$ conditions and sulfur content. They must be taken into account 346 when calculating Sm and Nd concentrations in bulk planetary silicate reservoirs. A late 347 addition of sulfide (FeS) to the segregating core, as proposed by Wohlers and Wood 348 (2015), would change the final Sm and Nd concentrations of the BSE since the partition 349 coefficients increase by three orders of magnitude from pure Fe metal to pure FeS. 350 However, Sm and Nd cannot be fractionated during core formation in a Solar System 351 planetary body of any size.

\subsection{Refractory Lithophile Element enrichment factor for the Earth calculated}

\section{4 from metal/silicate partitioning experiments}

355 Concentrations of refractory lithophile elements in the BSE are conventionally 356 estimated by comparing the chemical composition of the most pristine peridotites 357 (xenoliths and peridotite massifs) representative of the upper mantle and that of 358 chondrites. The traditional Earth composition models have been based on CI chondrites 359 because their bulk composition closely matches the composition of the solar 360 photosphere, except for the most volatile elements. REE concentrations in the BSE are 361 commonly defined using the RLE enrichment factor (EF), which is applied to all 362 refractory lithophile elements considered to be present in the BSE (similar to primitive 363 mantle) in chondritic proportions. When expressed relative to the concentration 364 measured in CI chondrites, this RLE factor lies within the range of 1.7 to 2.8 (Table 3). 
365 The determination of this EF is a key feature of most BSE model since non-refractory 366 and non-lithophile element concentrations in the BSE are determined via their observed 367 mantle ratio with RLE. Therefore, the enrichment of the BSE in RLE will dictate the 368 concentration of the BSE in all elements.

369 Here we propose a new approach where the RLE enrichment factor is calculated from 370 the experimental molten metal - silicate liquid REE partitioning results. We have 371 developed a model of planetary accretion focusing on the partitioning of REE between 372 the mantle and the core throughout Earth's formation. In this model, the Earth accreted 373 from impactors with a given chemical composition, which then equilibrate (fully or 374 partially) with the magma ocean of the proto-Earth, until the planet obtains its final 375 mass $\left(\mathrm{M}_{\mathrm{E}}=5.97 \cdot 10^{24} \mathrm{~kg}\right)$. All the scenarios result in a fully formed Earth, with a 376 primitive mantle representing $68 \%$ of its mass, the core representing the last $32 \%$. The 377 model takes into account the composition of various building blocks potentially 378 involved over the entire history of the Earth's accretion and metal/silicate partitioning 379 data which evolve with core formation conditions $\left(f_{\mathrm{o}_{2}}\right.$, pressure, temperature, 380 composition). The accretion model is described in detail in Appendix E.

382 The measurement of small variations in mass-independent stable isotope ratios for a 383 large number of elements, also called nucleosynthetic anomalies, provides a real 384 opportunity to investigate the genetic relationship between the different planetesimals 385 and planets. Several mixtures of different building blocks (which differ in nature and 386 proportions) have been proposed in previous studies to match the terrestrial isotopic 387 signature (e.g. Dauphas et al., 2014; Lodders, 2000). Results vary mainly because 388 different studies focused on different elements. However, most of the studies which 
integrate a large database of isotopic ratios agree on a major contribution of enstatite chondrites in the mixture with a smaller contribution of carbonaceous chondrites and/or 391 ordinary chondrites (Warren, 2011; Dauphas 2017; Liebske and Khan, 2019). We 392 assume that Earth accreted materials with bulk chondrite composition from known type 393 of meteorites and potential effects of collisional erosion on the chemical composition 394 are not considered (see Palme and O’Neill, 2014).

396 Among the available models, only those with a mixture of different building blocks (of 397 chondritic composition) that succeed in reproducing the Earth's isotopic signature are 398 considered (e.g. Dauphas, 2017; Warren, 2011). In order to further test the validity of 399 the accretion scenarios, we also studied the evolution of certain element ratios whose 400 molten metal-silicate liquid partitioning behaviour is well constrained in the literature: $401 \mathrm{Ni} / \mathrm{Co}, \mathrm{Nb} / \mathrm{Ta}$, and $\mathrm{Th} / \mathrm{U}$. Accretion scenarios must be able to reproduced these 402 elementary ratios already well established for the BSE $(\mathrm{Nb} / \mathrm{Ta}=14.0 \pm 0.60 ; \mathrm{Th} / \mathrm{U}=$ 403 3.78 $\pm 0.12 ; \mathrm{Ni} / \mathrm{Co}=18.90 \pm 0.30$, Munker, 2003; Palme and O’Neill, 2014; Wipperfurth 404 et al., 2018). The parameterisations used to constrain the behavior of these elements 405 during metal-silicate partitioning are taken from Fischer et al. (2015) for Ni and Co, 406 Cartier et al. (2014) for $\mathrm{Nb}$ and Ta and Faure et al., (2020) for U and Th. Of all the 407 accretion scenarios tested, only those reproducing (within $2 \sigma$ uncertainties) the BSE 408 elemental ratios are considered in the following discussion (Dauphas, 2017; Dauphas et 409 al., 2014; Lodders, 2000; Warren, 2011). These four accepted scenarios contain for the 410 building blocks between 70 and $91 \%$ of EC, the rest being made more oxidized (CC or 411 OC) materials (Table 4). Several models involving different building blocks mixture fail 
412 at reproducing the BSE elementary ratios (Javoy, 1995; Burbine and O'Brien, 2004;

413 Javoy et al., 2010; Fitoussi and Bourdon, 2012).

415 Rare earth element concentrations in the BSE for these four accepted scenarios are

416 reported in Table 4. Enrichment factors (EF) can be calculated from the comparison of 417 these BSE compositions with CI chondrites concentrations. However, it must be noted 418 that none of the measured chondrite compositions have so far succeeded in reproducing 419 the Earth's depletion in volatile elements compared to CI, as the Earth is more depleted 420 in those elements than any known chondrite (Allègre et al., 2001; Braukmüller et al., 421 2019; Wang et al., 2016). While it has been suggested that the Earth's depletion in 422 volatile elements could be the result of erosion following a giant impact during late 423 accretion (Halliday, 2004; Hubbard and Ebel, 2014), it has also been proposed that this 424 depletion pattern was already present in the Earth's building blocks (Birck et al., 1999; 425 Siebert et al., 2018, and references therein). The depletion of the Earth in volatiles 426 elements, no matter its occurrence in the planet history, would have a direct impact on 427 the concentration of RLE within the BSE. In order to take the impact of volatile 428 depletion on RLE concentrations in the resulting BSE into account, the concentration of 429 volatile elements in chondrites has been recalculated in order to fit the Earth's volatile430 element depletion pattern. This concerns volatile and moderately volatile elements, i.e. 431 those with 50\% condensation temperatures below $1230 \mathrm{~K}$ (Lodders, 2003). The 432 composition of non-refractory elements for each chondrite group has been recalculated, 433 by applying the primitive mantle (BSE) ratios when normalized to Mg (Lyubetskaya 434 and Korenaga, 2007; Palme and O’Neill, 2014). Then, concentrations of all elements 435 were recalculated to reach $100 \%$ weight total. The resulting compositions are found to 
436 be enriched in RLE compared to measured chondrite compositions by a factor $f_{\text {dry }}$ 437 ranging from 1.6 for $\mathrm{EH}$ chondrites, to 2.0 for $\mathrm{CM}$ chondrites (Appendix E). A 438 weighted average of these $f_{\text {dry }}$ factors, depending on the respective proportion of each 439 chondrite composition in the Earth's building blocks (Table 4), was applied to our 440 calculations.

442 Calculated enrichment factors are reported in Table 4 for the four accepted scenarios 443 corresponding to those proposed by Dauphas, (2017), Dauphas et al., (2014), Lodders, 444 (2000) and Warren, (2011). Values are identical within error and the average $\mathrm{EF}_{d r y}$ 445 value is 2.88 (Figure 6). The effect of volatile depletion shown in the figure is 446 significant, increasing the enrichment factor by a value of about 1 . Compared to the 447 concentrations given by previous authors (Table 3, Figure 6), our results are in 448 agreement with BSE composition models based on a geo-petrological approach, 449 showing high RLE concentrations (McDonough and Sun, 1995; Palme and O'Neill, 450 2014). McDonough and Sun (1995) use plots of $\mathrm{Ca} / \mathrm{Yb}, \mathrm{Sc} / \mathrm{Yb}$ and $\mathrm{Sm} / \mathrm{Yb}$ of fertile 451 lherzolites $(\mathrm{MgO} \leq 40.5 \mathrm{wt} \%)$ against a $\mathrm{TiO}_{2}$ content of the $\mathrm{BSE}$ set at $0.2 \mathrm{wt} . \%$ to 452 estimate the absolute proportions $(\mathrm{EF}=2.75)$. Palme and O'Neill (2014) use a mass 453 balance approach to calculate the primitive mantle composition. By first estimating the 454 major oxide concentrations in the primitive mantle $\left(\mathrm{MgO}, \mathrm{SiO}_{2}\right.$ and $\left.\mathrm{FeO}\right)$, they deduce 455 the amount of the two RLE oxides, $\mathrm{CaO}$ and $\mathrm{Al}_{2} \mathrm{O}_{3}$, using their chondritic ratios. They 456 obtain an RLE enrichment factor of $2.83 \pm 0.23$. The two other BSE models presented in 457 Figure 6 yield lower enrichment factors. Lyubetskaya and Korenaga, (2007), by 458 reassessing the peridotite database from McDonough and Sun (1995), obtain an RLE 459 enrichment factor of the BSE of $2.16 \pm 0.37$. This value overlaps with the $\mathrm{EF}_{\text {dry }}$ factor 
460 obtained following the model proposed by Dauphas et al. (2014) (Figure 6). The 461 difference with McDonough and Sun, (1995)'s results is due to the statistical treatment 462 of the database, specifically the selection criteria of pristine samples (metasomatism, 463 melt extraction) and the statistical data filtering

465 In the model proposed by Allègre et al. (2001), concentrations of refractory elements in 466 the BSE are significantly lower and the calculated enrichment factor is within the range 467 of those calculated from models that do not consider the volatility trend of the BSE 468 (open circles in Figure 6). Allègre et al. (2001) use $\mathrm{Mg} / \mathrm{Si}$ and $\mathrm{Al} / \mathrm{Mg}$ ratios for the least 469 differentiated sample of Earth's mantle of 0.945 and 0.095 , respectively, taken from 470 Hart and Zindler, (1986). Trace element concentrations are then calculated based on the 471 cosmochemical trend shown by carbonaceous chondrites (and sometime other chondrite 472 groups) in a trace element ratio plot. This model requires very few assumptions and 473 succeeds in reproducing the depletion trend of the Earth's volatile elements. However, 474 when estimating the Earth's RLE concentrations using the ratio trends of these elements 475 in chondrites, this method fails to take into account the relative enrichment in refractory 476 elements of the BSE compared to chondrites due to volatile element loss. Thus they 477 obtain a BSE composition enriched in REE by an average of $1.70 \pm 0.24$ compared to 478 CI.

\subsection{Generalisation of the enrichment factor to all RLE?}

481 Most BSE models assume fixed chondrite-normalized RLE ratios. While we show that 482 this hypothesis is relevant for REE from La to Gd (except Eu under specific conditions), 483 some elements usually classified as RLE may change their behavior at core-forming 
conditions $\left(\mathrm{P}, \mathrm{T}, \mathrm{fo}_{2}\right)$. For example, $\mathrm{Nb}$ and $\mathrm{Ta}$ are both siderophile elements in reduced conditions. Heterogeneous accretion models in which conditions evolve from reduced to oxidized during the Earth's accretion explain the superchondritic $\mathrm{Nb} / \mathrm{Ta}$ ratio of the BSE (Cartier et al., 2014). Therefore, the RLE enrichment factor presented here should only be used to calculate the abundances of elements that are known to remain lithophile under Earth accretion conditions. Within the REE group, two elements are likely to behave differently: Eu and Yb. Data on heavy REE are available in the study of 491 Ingrao et al. (2019) and Wohlers and Wood (2017). In a similar fashion to Eu in a sulfur 492 rich environment, $\mathrm{Yb}$ fractionation occurs in very reduced conditions (IW -5 to -7 ) and 493 the partial reduction to a +2 valence state has been identified using X-ray Absorption 494 Near Edge Structure measurements (Ingrao et al., 2019). However, since Eu is more 495 sensitive than $\mathrm{Yb}$ to a valence change under reduced conditions, and no significant 496 fractionation between Eu and other studied REE is observed, we do not anticipate that 497 core formation would cause an $\mathrm{Yb}$ anomaly in the calculated BSE REE pattern. 498 Furthermore, the $\mathrm{S}$ content of the Earth's core is considered to be about $2 \mathrm{wt} \%$ from 499 geophysical, geochemical and cosmochemical constraints (e.g. (Allègre et al., 2001; 500 Boujibar et al., 2014). There is still debate as to whether the Earth's core acquired its 501 sulfur signature over the entire accretion history, or exclusively in the last $10-20 \%$ of 502 the Earth's accretion (e.g. Wood and Halliday, 2005). In order to consider the impact of 503 the accretion of sulfur-rich bodies on the concentration of REE in the different 504 reservoirs, we ran models representing several scenarios involving impactors containing 505 iron sulfide instead of metallic iron, in various proportions (up to $20 \%$ of the Earth's 506 mass). No significant variation in REE concentrations or ratios within the BSE is 
observed. The addition of sulfide to the Earth's core, at any time during the Earth's accretion, leaves no noticeable trace on the resulting REE concentrations of the BSE.

\subsection{Chemical uniformity of present day mantle?}

511 BSE composition models based on the analysis of the upper mantle rocks consider 512 samples from the upper mantle to be chemically representative of the mantle as a whole. 513 However, it has been proposed that a substantial difference exists between a pyrolitic 514 upper mantle and the lower mantle, below the $660 \mathrm{~km}$ seismic discontinuity, particularly 515 in terms of $\mathrm{Mg} / \mathrm{Si}$ and $\mathrm{Mg} / \mathrm{Fe}$ (Ringwood, 1989). Various evidences have been used to 516 infer a lower mantle chemically distinct from the upper mantle in terms of major and 517 trace elements. Among them, the isotopic and chemical heterogeneities measured in 518 mantle-derived basalts. Measured isotopic ratios support the existence of early-formed 519 chemical heterogeneities that could be preserved in the deepest part of the mantle.

520 Furthermore, the apparent mismatch between laboratory-measured properties in upper 521 mantle composition assemblage and the seismic and other geophysical properties 522 observed in the lower mantle, coupled with the identification of a global seismic 523 discontinuity at $660 \mathrm{~km}$ depth and early interpretations of the density of the lower 524 mantle led to the design of a two chemically distinct layers model of Earth's mantle (see 525 Hofmann, 2014 for a review).

527 However, one compelling observation in favor of a homogeneous mantle is tomographic 528 images showing slabs of oceanic lithosphere descending through the lower mantle 529 (Fukao and Obayashi, 2013). Furthermore, recent studies combining mineral physics 530 data with seismological constraints support the idea that the lower mantle is most likely 
pyrolytic and that there is no need for a chemically stratified mantle (Hyung et al., 2016;

532 Zhang et al., 2013). While it has been suggested that the Earth's layers could affect just

533 the bulk mantle trace element budget (Campbell and O'Neill, 2012), our models show

534 that REE abundances estimated for upper mantle samples are well reproduced by the

535 resulting BSE using accretion models with isotopically-supported building block

536 mixing. This supports the argument in favor of a chemically uniform mantle.

\section{Conclusion}

539 Molten metal - silicate liquid partitioning data have been obtained from 24 multi-anvil

540 experiments on rare earth elements from La to $\mathrm{Gd}$. These elements are lithophile under

541 the conditions of Earth accretion, with molten metal - silicate liquid partition 542 coefficients ranging from $10^{-2}$ to $10^{-6}$. Their partitioning behaviour is mainly constrained

543 by the oxygen fugacity and the $\mathrm{S}$ concentration in the metallic phase of the system.

544 Using our data, together with previously published results, we obtain a two-variable

545 parameterisation for these elements. They are trivalent during the Earth's accretion,

546 even at low oxygen fugacity conditions, with the exception of Eu, which is divalent.

547 Our results show that $\mathrm{Sm}$ and $\mathrm{Nd}$ are not significantly fractionated by core formation

548 processes over a large range of $f_{\mathrm{O}_{2}}$ conditions, even in the presence of a large quantity of

549 sulfur. The main impact of core formation is to concentrate the REE within the BSE.

550 The absolute REE concentration in the BSE depends on the nature of the building

551 blocks involved in the accretion scenario. Accretion scenarios using mixtures of 552 chondrites that match the nucleosynthetic signature of the Earth give an average 553 enrichment factor of 2.88 relative to CI. This result takes into account the RLE 554 enrichment of the BSE due to the Earth's depletion in volatile elements compared to 
555 chondrites. Our estimate is in good agreement with those of McDonough and Sun 556 (1995) and Palme and O’Neill, (2014), and in favor of a chemically homogeneous 557 present day mantle. This enrichment factor can be extended to other elements which 558 remain strictly lithophile during Earth core formation. The formation of the core, with

559 or without segregation of a sulfide phase, cannot be responsible for the small ${ }^{142} \mathrm{Nd}$ 560 excess measured in modern terrestrial samples relative to chondrites.

\section{Acknowledgments}

563 Detailed reviews by two anonymous reviewers are much appreciated as are the editorial 564 comments and handling by James Badro. This project has received funding from the 565 European Research Council (ERC) under the European Union's Horizon 2020 research 566 and innovation program (Grant Agreement No. 682778 - ISOREE). The multi-anvil 567 apparatus of Laboratoire Magmas et Volcans is financially supported by the CNRS 568 (Instrument national de l'INSU). This is also the French Government Laboratory of 569 Excellence Initiative $N^{\circ}$ ANR-10_LABX-006, the Région Auvergne and the European 570 Regional Development Fund. This is Laboratory of Excellence ClerVolc contribution $571 \quad \mathrm{~N}^{\circ} \mathrm{xxx}$

\section{References}

574 Achterberg, E. van, Ryan, C.G., Jackson, S., and Griffin, W.L. (2001). Data reduction software for LA-ICP-MS. In Laser-Ablation- ICPMS in the Earth Sciences, Principles and Applications, 239-243.

577 Allègre, C., Manhès, G., and Lewin, É. (2001). Chemical composition of the Earth and 578 the volatility control on planetary genetics. Earth and Planetary Science Letters 
Andreasen, R., Sharma, M., Subbarao, K.V., and Viladkar, S.G. (2008). Where on Earth is the enriched Hadean reservoir? Earth and Planetary Science Letters 266, 14-28.

Birck, J.L., Rotaru, M., and Allègre, C.J. (1999). 53Mn-53Cr evolution of the early solar system. Geochimica et Cosmochimica Acta 63, 4111-4117.

Bouhifd, M.A., Boyet, M., Cartier, C., Hammouda, T., Bolfan-Casanova, N., Devidal, J.L., and Andrault, D. (2015). Superchondritic Sm/Nd ratio of the Earth: Impact of Earth's core formation. Earth and Planetary Science Letters 413, 158-166.

Boujibar, A., Andrault, D., Bouhifd, M.A., Bolfan-Casanova, N., Devidal, J.-L., and Trcera, N. (2014). Metal-silicate partitioning of sulphur, new experimental and thermodynamic constraints on planetary accretion. Earth and Planetary Science Letters $391,42-54$.

Boyet, M., and Carlson, R.W. (2005). 142Nd Evidence for Early (\&gt;4.53 Ga) Global Differentiation of the Silicate Earth. Science 309, 576-581.

Boyet, M., Bouvier, A., Frossard, P., Hammouda, T., Garçon, M., and Gannoun, A. (2018). Enstatite chondrites EL3 as building blocks for the Earth: The debate over the 146 Sm- 142 Nd systematics. Earth and Planetary Science Letters 488, 68-78.

Braukmüller, N., Wombacher, F., Funk, C., and Münker, C. (2019). Earth's volatile element depletion pattern inherited from a carbonaceous chondrite-like source. Nature Geoscience 12, 564-568.

Burbine, T.H., O’Brien, K.M., 2004. Determining the possible building blocks of the Earth and Mars. Meteorit. Planet. Sci. 39, 667-681.

Burnham, A.D., Berry, A.J., Halse, H.R., Schofield, P.F., Cibin, G., and Mosselmans, J.F.W. (2015). The oxidation state of europium in silicate melts as a function of 
604 Campbell, I.H., and St C. O’Neill, H. (2012). Evidence against a chondritic Earth. $605 \quad$ Nature 483, 553-558.

606 Cartier, C., Hammouda, T., Boyet, M., Bouhifd, M.A., and Devidal, J.-L. (2014). Redox 607 control of the fractionation of niobium and tantalum during planetary accretion 608 and core formation. Nature Geoscience 7, 573-576.

Dauphas, N. (2017). The isotopic nature of the Earth's accreting material through time. Nature 541, 521-524.

611 Dauphas, N., Chen, J.H., Zhang, J., Papanastassiou, D.A., Davis, A.M., and Travaglio, C. (2014). Calcium-48 isotopic anomalies in bulk chondrites and achondrites: Evidence for a uniform isotopic reservoir in the inner protoplanetary disk. Earth and Planetary Science Letters 407, 96-108.

Faure, P., Bouhifd, M.A., Boyet, M., Manthilake, G., Clesi, V., and Devidal, J.-L. (2020). Uranium and thorium partitioning in the bulk silicate Earth and the oxygen content of Earth's core. Geochimica et Cosmochimica Acta 275, 83-98.

618 Fischer, R.A., Nakajima, Y., Campbell, A.J., Frost, D.J., Harries, D., Langenhorst, F., Miyajima, N., Pollok, K., and Rubie, D.C. (2015). High pressure metal-silicate partitioning of Ni, Co, V, Cr, Si, and O. Geochimica et Cosmochimica Acta 167, $177-194$.

Fitoussi, C., and Bourdon, B. (2012). Silicon Isotope Evidence Against an Enstatite Chondrite Earth. Science 335, 1477-1480.

624 Fukao, Y., and Obayashi, M. (2013). Subducted slabs stagnant above, penetrating through, and trapped below the $660 \mathrm{~km}$ discontinuity: subducted slabs in the transitions zone. Journal of Geophysical Research: Solid Earth 118, 5920-5938. 
Gagnon, J.E., Fryer, B.J., Samson, I.M., and Williams-Jones, A.E. (2008). Quantitative analysis of silicate certified reference materials by LA-ICPMS with and without an internal standard. Journal of Analytical Atomic Spectrometry 23, 1529.

Halliday, A.N. (2004). Mixing, volatile loss and compositional change during impactdriven accretion of the Earth. Nature 427, 505-509.

Hammouda, T. (2003). High-pressure melting of carbonated eclogite and experimental constraints on carbon recycling and storage in the mantle. Earth and Planetary Science Letters 214, 357-368.

Hart, S.R., and Zindler, A. (1986). In search of a bulk-Earth composition. Chemical Geology 57, 247-267.

Hofmann, A. (2014). Sampling Mantle Heterogeneity through Oceanic Basalts: Isotopes and Trace Elements. Treatise on Geochemistry 2, 67-101.

Holzheid, A., Palme, H., and Chakraborty, S. (1997). The activities of NiO, CoO and FeO in silicate melts. Chemical Geology 139, 21-38.

Hubbard, A., and Ebel, D.S. (2014). Protoplanetary dust porosity and FU Orionis outbursts: Solving the mystery of Earth's missing volatiles. Icarus 237, 84-96.

Hyung, E., Huang, S., Petaev, M.I., and Jacobsen, S.B. (2016). Is the mantle chemically stratified? Insights from sound velocity modeling and isotope evolution of an early magma ocean. Earth and Planetary Science Letters 440, 158-168.

Ingrao, N.J., Hammouda, T., Boyet, M., Gaborieau, M., Moine, B.N., Vlastelic, I., Bouhifd, M.A., Devidal, J.-L., Mathon, O., Testemale, D., et al. (2019). Rare Earth Element Partitioning Between Sulphides and Melt: Evidence for $\mathrm{Yb} 2+$ and $\mathrm{Sm} 2+$ in EH Chondrites. Geochimica et Cosmochimica Acta. 
Javoy, M., Kaminski, E., Guyot, F., Andrault, D., Sanloup, C., Moreira, M., Labrosse, S., Jambon, A., Agrinier, P., Davaille, A., Jaupart, C., 2010. The chemical composition of the Earth: enstatite chondrite models. Earth Planet. Sci. Lett. 293 (3-4), 259-268.

Jellinek, A.M., Jackson, M.G. (2015). Connections between the bulk composition, geodynamics and habitability of Earth. Nature Geoscience, 8(8), 587-593.

Li, J., Hadidiacos, C., Mao, H.-K., Fei, Y., and Hemley, R.J. (2003). Behavior of thermocouples under high pressure in a multi-anvil apparatus. High Pressure Research 23, 389-401.

Liebske, C., and Khan, A. (2019). On the principal building blocks of Mars and Earth. Icarus $322,121-134$.

Lodders, K. (1996). An experimental and theoretical study of rare earth element partitioning between sulfides (FeS, $\mathrm{CaS})$ and silicate and application to enstatite achondrites. Meteoritics and Planetary Science 31, 749-766.

Lodders, K. (2000). An Oxygen Isotope Mixing Model for the Accretion and Composition of Rocky Planets. Space Science Reviews 92, 341-354.

Lodders, K. (2003). Solar System Abundances and Condensation Temperatures of the Elements. The Astrophysical Journal 591, 1220-1247.

Lyubetskaya, T., and Korenaga, J. (2007). Chemical composition of Earth's primitive mantle and its variance. Journal of Geophysical Research 112.

Ma, Z. (2001). Thermodynamic description for concentrated metallic solutions using interaction parameters. Metallurgical and Materials Transactions B 32, 87-103.

McDonough, W.F., and Sun, S. -s (1995). The composition of the Earth. Chemical Geology 120, 223-253. 
674 Munker, C. (2003). Evolution of Planetary Cores and the Earth-Moon System from $\mathrm{Nb} / \mathrm{Ta}$ Systematics. Science 301, 84-87.

676 Palme, H., and O'Neill, H.St.C. (2014). Cosmochemical Estimates of Mantle 677 Composition. In Treatise on Geochemistry, (Elsevier), 1-39.

678 Righter, K., Pando, K.M., Danielson, L., and Lee, C.-T. (2010). Partitioning of Mo, P 679 and other siderophile elements $(\mathrm{Cu}, \mathrm{Ga}, \mathrm{Sn}, \mathrm{Ni}, \mathrm{Co}, \mathrm{Cr}, \mathrm{Mn}, \mathrm{V}$, and $\mathrm{W})$ between 680 metal and silicate melt as a function of temperature and silicate melt composition. $681 \quad$ Earth and Planetary Science Letters 291, 1-9.

682 Ringwood, A.E. (1989). Significance of the terrestrial Mg/Si ratio. Earth and Planetary 683 Science Letters 95, 1-7.

684 Rubin, A.E. (1983). Impact melt-rock clasts in the Hvittis enstatite chondrite breccia685 Implications for a genetic relationship between EL chondrites and aubrites. In 686 Lunar and Planetary Science Conference Proceedings, B293-B300.

Saji, N.S., Wielandt, D., Paton, C., and Bizzarro, M. (2016). Ultra-high-precision Nd688 isotope measurements of geological materials by MC-ICPMS. Journal of Analytical Atomic Spectrometry 31, 1490-1504.

Siebert, J., Corgne, A., and Ryerson, F.J. (2011). Systematics of metal-silicate partitioning for many siderophile elements applied to Earth's core formation. Geochimica et Cosmochimica Acta 75, 1451-1489.

693 Siebert, J., Sossi, P.A., Blanchard, I., Mahan, B., Badro, J., and Moynier, F. (2018). 694 Chondritic $\mathrm{Mn} / \mathrm{Na}$ ratio and limited post-nebular volatile loss of the Earth. Earth and Planetary Science Letters 485, 130-139.

696 Suer, T.-A., Siebert, J., Remusat, L., Menguy, N., Fiquet, G., 2017. A sulfur-poor 697 terrestrial core inferred from metal-silicate partitioning experiments. Earth Planet. 
Toplis, M.J. (2004). The thermodynamics of iron and magnesium partitioning between olivine and liquid: criteria for assessing and predicting equilibrium in natural and experimental systems. Contributions to Mineralogy and Petrology 149, 22-39.

Wade, J., and Wood, B.J. (2005). Core formation and the oxidation state of the Earth. 703 Earth and Planetary Science Letters 236, 78-95.

Wang, Z., Laurenz, V., Petitgirard, S., and Becker, H. (2016). Earth's moderately 705 volatile element composition may not be chondritic: Evidence from $\mathrm{In}, \mathrm{Cd}$ and Zn. Earth and Planetary Science Letters 435, 136-146.

Warren, P.H. (2011). Stable-isotopic anomalies and the accretionary assemblage of the Earth and Mars: A subordinate role for carbonaceous chondrites. Earth and Planetary Science Letters 311, 93-100.

Wipperfurth, S.A., Guo, M., Šrámek, O., and McDonough, W.F. (2018). Earth's chondritic $\mathrm{Th} / \mathrm{U}$ : Negligible fractionation during accretion, core formation, and crust-mantle differentiation. Earth and Planetary Science Letters 498, 196-202.

Wohlers, A., and Wood, B.J. (2015). A Mercury-like component of early Earth yields uranium in the core and high mantle ${ }^{142} \mathrm{Nd}$. Nature 520, 337-340.

Wohlers, A., and Wood, B.J. (2017). Uranium, thorium and REE partitioning into sulfide liquids: Implications for reduced S-rich bodies. Geochimica et Cosmochimica Acta 205, 226-244.

721 Wood, B.J., and Halliday, A.N. (2005). Cooling of the Earth and core formation after 

the giant impact. Nature 437, 1345-1348.

723 Zhang, Z., Stixrude, L., and Brodholt, J. (2013). Elastic properties of MgSiO3724 perovskite under lower mantle conditions and the composition of the deep Earth. Earth and Planetary Science Letters 379, 1-12.

726 
Figure Captions

Figure 1. Backscattered electron image of the sample \#1322, recovered from a $6 \mathrm{GPa}$ and $2503 \mathrm{~K}$ experiment in a graphite capsule.

Figure 2. Evolution of metal-silicate partition coeffcients for neodymium and europium $\left(\mathrm{D}_{\mathrm{Nd}}\right.$ and $\left.\mathrm{D}_{\mathrm{Eu}}\right)$ with $\log f_{\mathrm{O}_{2}}$. Datapoints are from this study (Appendix $\mathrm{A}$ ) and from the litterature (Apprendix B). Data are corrected for the effect of metalic sulfur using the parametrization presented in equation 6 and Table 2. Similar binary plots for other studied REE are given in Appendix D.1. Dashed line represents fitted linear regression, in agreement with equation 6 and parameters values displayed in Table 2.

Figure 3. Evolution of metal-silicate partition coefficients for neodymium and

740 europium $\left(\mathrm{D}_{\mathrm{Nd}}\right.$ and $\left.\mathrm{D}_{\mathrm{Eu}}\right)$ with the $\mathrm{S}$ concentration in the metal. Datapoints are from this

741 study (Appendix A) and from the litterature (Apprendix C). Data are corrected for the 742 effect of oxygen fugacity using the parametrization presented in equation 6 and Table 2 .

743 Similar binary plots for other studied REE are given in Appendix D.1. Dashed line 744 represents fitted linear regression, in agreement with equation 6 and parameters values 745 displayed in Table 2.

747 Figure 4. Sulfur-silicate partition coefficients for REE (normalized to $\mathrm{D}_{\mathrm{Nd}}$ ) determined 748 in all S-rich experiments (Xs from 25.3 to $35.2 \mathrm{wt}$ \%). The average sulfur-silicate 749 partition coefficients from Ingrao et al. (2019), Lodders (1996) and Wohlers and Wood 750 (2017) are also plotted. Error bars are not shown for clarity, but $\mathrm{D}_{\mathrm{Eu}}$ values are 
751 significantly distinct from those of other REE (with the exception of experiment \#509 752 and Wohlers and Wood, 2017).

753

754 Figure 5. Ratio of metal-silicate partition coefficients determined for $\mathrm{Sm}$ and $\mathrm{Nd}$ $755\left(\mathrm{D}_{\mathrm{Sm}} / \mathrm{D}_{\mathrm{Nd}}\right)$ as a function of oxygen fugacity. Data presented are from this study as well 756 as those from the literature for experiments performed over the chondritic liquidus. 757 Error bars display the $1 \sigma$ uncertainties on original data. These samples present $\mathrm{S}$ 758 contents in the metallic phase ranging from 0 to $35 \mathrm{wt} . \%$.

759

760 Figure 6. RLE enrichment factors of the BSE calculated from accretion scenarios using 761 mixtures of different chondritic building blocks, compared with published BSE 762 composition models. Open circles represent RLE enrichment factors determined from 763 our accretion model in the BSE using measured chondrite compositions. Higher values 764 of RLE enrichment factors (noted $\mathrm{EF}_{\text {dry }}$ in Table 4) are obtained when the volatile 765 depletion is taken into account. BSE enrichment factors in RLE ( $\left.\mathrm{EF}_{\text {dry }}\right)$ are well 766 reproduced by BSE composition from McDonough and Sun, (1995) and Palme and 767 O'Neill, (2014). 
Table 1. Experimental conditions $\left(\mathrm{P}, \mathrm{T}, f_{\mathrm{O}_{2}}\right)$ and metal-silicate partition coefficients of REE (La to Gd) for the different samples. Given uncertainties are 1 sigma. For this work, different doping solutions were synthesized. Type A solution contained La, Ce, Pr, Nd and Sm, while type B solution contained Nd, Sm, Eu and Gd. For sulphur-rich experiments, a type $\mathrm{C}$ solution containing all $7 \mathrm{REE}$ from La to Gd was prepared. ${ }^{*}$ Temperature determined using the power/temperature relation deduced from previous experiments.

\begin{tabular}{|c|c|c|c|c|c|c|c|c|c|c|c|c|}
\hline Run & Capsule & Doping solution & $\mathbf{P}(\mathbf{G P a})$ & $T(K)$ & $\log f \mathbf{o}_{2}(\Delta \mathrm{IW})$ & $\mathbf{D}_{\mathrm{La}}$ & $\mathbf{D}_{\mathrm{Ce}}$ & $\mathbf{D}_{\mathrm{Pr}}$ & $\mathbf{D}_{\mathrm{Nd}}$ & $\mathbf{D}_{\mathrm{Sm}}$ & $\mathbf{D}_{\mathrm{Eu}}$ & $\mathbf{D}_{\mathrm{Gd}}$ \\
\hline 509 & Graphite & $\mathrm{C}$ & 6 & 2361 & -0.60 & $\begin{array}{c}6.19 \times 10^{-4} \\
\pm 1.63 \times 10^{-4}\end{array}$ & $\begin{array}{c}1.01 \times 10^{-3} \\
\pm 1.33 \times 10^{-4}\end{array}$ & $\begin{array}{c}9.28 \times 10^{-4} \\
\pm 1.23 \times 10^{-4}\end{array}$ & $\begin{array}{c}9.98 \times 10^{-4} \\
\pm 1.67 \times 10^{-4}\end{array}$ & $\begin{array}{c}9.49 \times 10^{-4} \\
\pm 1.88 \times 10^{-4}\end{array}$ & $\begin{array}{c}1.31 \times 10^{-3} \\
\pm 1.86 \times 10^{-4}\end{array}$ & $\begin{array}{c}7.16 \times 10^{-4} \\
\pm 2.09 \times 10^{-4}\end{array}$ \\
\hline 536 & Graphite & $\mathrm{C}$ & 6 & 2386 & -0.47 & $\begin{array}{c}1.40 \times 10^{-3} \\
\pm 8.24 \times 10^{-5}\end{array}$ & $\begin{array}{r}2.35 \times 10^{-3} \\
\pm 3.70 \times 10^{-4}\end{array}$ & $\begin{array}{c}1.98 \times 10^{-3} \\
\pm 1.55 \times 10^{-4}\end{array}$ & $\begin{array}{c}1.86 \times 10^{-3} \\
\pm 5.95 \times 10^{-5}\end{array}$ & $\begin{array}{c}1.49 \times 10^{-3} \\
\pm 1.85 \times 10^{-4}\end{array}$ & $\begin{array}{c}4.95 \times 10^{-3} \\
\pm 3.14 \times 10^{-4}\end{array}$ & $\begin{array}{r}8.33 \times 10^{-4} \\
\pm 5.88 \times 10^{-5}\end{array}$ \\
\hline 581 & Graphite & $\mathrm{C}$ & 6 & $2563^{*}$ & -0.86 & $\begin{array}{c}4.24 \times 10^{-4} \\
\pm 8.44 \times 10^{-5}\end{array}$ & $\begin{array}{c}5.86 \times 10^{-4} \\
\pm 1.16 \times 10^{-4}\end{array}$ & $\begin{array}{c}5.41 \times 10^{-4} \\
\pm 8.95 \times 10^{-5}\end{array}$ & $\begin{array}{c}4.81 \times 10^{-4} \\
\pm 9.93 \times 10^{-5}\end{array}$ & $\begin{array}{c}3.56 \times 10^{-4} \\
\pm 5.16 \times 10^{-5}\end{array}$ & $\begin{array}{c}1.01 \times 10^{-3} \\
\pm 1.44 \times 10^{-4}\end{array}$ & $\begin{array}{c}2.10 \times 10^{-4} \\
\pm 2.16 \times 10^{-4}\end{array}$ \\
\hline 594 & Graphite & B & 6 & 2388 & -3.18 & & & & $\begin{array}{r}1.76 \times 10^{-4} \\
\pm 1.48 \times 10^{-5}\end{array}$ & $\begin{array}{c}1.40 \times 10^{-4} \\
\pm 1.99 \times 10^{-5}\end{array}$ & $\begin{array}{c}2.19 \times 10^{-4} \\
\pm 1.77 \times 10^{-5}\end{array}$ & $\begin{array}{c}1.00 \times 10^{-4} \\
\pm 6.96 \times 10^{-6}\end{array}$ \\
\hline 596 & Graphite & B & 6 & 2499 & -3.40 & & & & $\begin{array}{r}3.38 \times 10^{-5} \\
\pm 1.04 \times 10^{-5} \\
\end{array}$ & $\begin{array}{r}3.50 \times 10^{-5} \\
\pm 5.11 \times 10^{-7} \\
\end{array}$ & $\begin{array}{c}2.46 \times 10^{-5} \\
\pm 5.02 \times 10^{-7} \\
\end{array}$ & $\begin{array}{r}2.61 \times 10^{-5} \\
\pm 9.61 \times 10^{-7} \\
\end{array}$ \\
\hline 598 & Graphite & A & 6 & 2543 & -1.47 & $\begin{array}{c}1.92 \times 10^{-5} \\
\pm 4.96 \times 10^{-6}\end{array}$ & $\begin{array}{c}1.79 \times 10^{-5} \\
\pm 1.71 \times 10^{-6}\end{array}$ & $\begin{array}{c}1.11 \times 10^{-5} \\
\pm 4.01 \times 10^{-6}\end{array}$ & $\begin{array}{c}1.10 \times 10^{-5} \\
\pm 1.77 \times 10^{-6}\end{array}$ & $\begin{array}{c}1.07 \times 10^{-5} \\
\pm 1.55 \times 10^{-6}\end{array}$ & & \\
\hline 599 & Graphite & A & 6 & 2532 & -3.26 & $\begin{array}{c}5.99 \times 10^{-5} \\
\pm 2.89 \times 10^{-5}\end{array}$ & $\begin{array}{c}8.24 \times 10^{-5} \\
\pm 1.42 \times 10^{-6}\end{array}$ & $\begin{array}{c}5.97 \times 10^{-5} \\
\pm 3.95 \times 10^{-6}\end{array}$ & $\begin{array}{c}6.76 \times 10^{-5} \\
\pm 5.17 \times 10^{-6}\end{array}$ & $\begin{array}{c}7.22 \times 10^{-5} \\
\pm 1.66 \times 10^{-5}\end{array}$ & & \\
\hline 600 & Graphite & A & 6 & 2536 & -2.81 & $\begin{array}{c}1.25 \times 10^{-5} \\
\pm 9.85 \times 10^{-6}\end{array}$ & $\begin{array}{c}2.22 \times 10^{-5} \\
\pm 9.56 \times 10^{-6}\end{array}$ & $\begin{array}{c}1.39 \times 10^{-5} \\
\pm 3.47 \times 10^{-6}\end{array}$ & $\begin{array}{c}2.09 \times 10^{-5} \\
\pm 4.65 \times 10^{-6}\end{array}$ & $\begin{array}{c}1.94 \times 10^{-5} \\
\pm 1.53 \times 10^{-6}\end{array}$ & & \\
\hline 601 & Graphite & A & 6 & 2517 & -3.58 & $\begin{array}{c}2.19 \times 10^{-5} \\
\pm 1.44 \times 10^{-5}\end{array}$ & $\begin{array}{c}4.87 \times 10^{-5} \\
\pm 1.82 \times 10^{-5}\end{array}$ & $\begin{array}{c}4.40 \times 10^{-5} \\
\pm 1.23 \times 10^{-5}\end{array}$ & $\begin{array}{c}5.00 \times 10^{-5} \\
\pm 1.70 \times 10^{-5}\end{array}$ & $\begin{array}{c}6.96 \times 10^{-5} \\
\pm 1.43 \times 10^{-5}\end{array}$ & & \\
\hline 603 & Graphite & B & 6 & 2500 & -3.48 & & & & $\begin{array}{c}2.66 \times 10^{-5} \\
\pm 4.41 \times 10^{-6}\end{array}$ & $\begin{array}{c}2.62 \times 10^{-5} \\
\pm 2.69 \times 10^{-6}\end{array}$ & $\begin{array}{c}2.21 \times 10^{-5} \\
\pm 3.12 \times 10^{-6}\end{array}$ & $\begin{array}{c}1.61 \times 10^{-5} \\
\pm 2.22 \times 10^{-6}\end{array}$ \\
\hline 685 & Graphite & $\mathrm{C}$ & 6 & $2529^{*}$ & -0.68 & $\begin{array}{c}1.02 \times 10^{-3} \\
\pm 3.73 \times 10^{-4}\end{array}$ & $\begin{array}{c}1.42 \times 10^{-3} \\
\pm 5.23 \times 10^{-4}\end{array}$ & $\begin{array}{c}1.33 \times 10^{-3} \\
\pm 4.68 \times 10^{-4}\end{array}$ & $\begin{array}{c}1.21 \times 10^{-3} \\
\pm 4.54 \times 10^{-4}\end{array}$ & $\begin{array}{c}1.02 \times 10^{-3} \\
\pm 4.01 \times 10^{-4}\end{array}$ & $\begin{array}{c}2.30 \times 10^{-3} \\
\pm 7.54 \times 10^{-4}\end{array}$ & $\begin{array}{c}6.40 \times 10^{-4} \\
\pm 2.70 \times 10^{-4}\end{array}$ \\
\hline 693 & $\begin{array}{c}\mathrm{MgO} \text { single } \\
\text { crystal }\end{array}$ & B & 14 & 2560 & -1.51 & & & & $\begin{array}{r}1.25 \times 10^{-9} \\
\pm 5.70 \times 10^{-6}\end{array}$ & $\begin{array}{c}1.18 \times 10^{-5} \\
\pm 2.64 \times 10^{-6}\end{array}$ & $\begin{array}{c}1.34 \times 10^{-5} \\
\pm 5.31 \times 10^{-6}\end{array}$ & $\begin{array}{l}8.47 \times 10-06 \\
\pm 3.43 \times 10^{-6}\end{array}$ \\
\hline 694 & Graphite & B & 6 & 2365 & -0.59 & & & & $\begin{array}{c}1.83 \times 10^{-5} \\
\pm 2.35 \times 10^{-6}\end{array}$ & $\begin{array}{c}1.77 \times 10^{-5} \\
\pm 2.22 \times 10^{-6}\end{array}$ & $\begin{array}{c}1.29 \times 10^{-5} \\
\pm 6.03 \times 10^{-6}\end{array}$ & $\begin{array}{c}.59 \times 10^{-5} \\
\pm 3.79 \times 10^{-5}\end{array}$ \\
\hline 696 & $\begin{array}{c}\mathrm{MgO} \text { single } \\
\text { crystal }\end{array}$ & A & 14 & $2560^{*}$ & -1.51 & $\begin{array}{c}2.61 \times 10^{-6} \\
\pm 1.26 \times 10^{-6}\end{array}$ & $\begin{array}{c}6.30 \times 10^{-6} \\
\pm 2.91 \times 10^{-6} \\
\end{array}$ & $\begin{array}{c}4.88 \times 10^{-6} \\
\pm 2.17 \times 10^{-6}\end{array}$ & $\begin{array}{r}5.36 \times 10^{-6} \\
\pm 1.84 \times 10^{-6} \\
\end{array}$ & $\begin{array}{c}6.17 \times 10^{-6} \\
\pm 2.57 \times 10^{-6}\end{array}$ & & \\
\hline 698 & Graphite & $\mathrm{C}$ & 6 & 2429 & -0.63 & $\begin{array}{r}2.74 \times 10^{-3} \\
\pm 5.05 \times 10^{-4} \\
\end{array}$ & $\begin{array}{c}3.44 \times 10^{-3} \\
\pm 5.44 \times 10^{-4}\end{array}$ & $\begin{array}{c}3.24 \times 10^{-3} \\
\pm 4.87 \times 10^{-4} \\
\end{array}$ & $\begin{array}{c}3.04 \times 10^{-3} \\
\pm 3.76 \times 10^{-4}\end{array}$ & $\begin{array}{c}2.74 \times 10^{-3} \\
\pm 3.12 \times 10^{-4}\end{array}$ & $\begin{array}{c}5.21 \times 10^{-3} \\
\pm 6.54 \times 10^{-4}\end{array}$ & $\begin{array}{c}2.06 \times 10^{-3} \\
\pm 2.80 \times 10^{-4}\end{array}$ \\
\hline 699 & Graphite & $\mathrm{C}$ & 6 & 2439 & -0.20 & $\begin{array}{c}4.01 \times 10^{-3} \\
\pm 3.42 \times 10^{-4}\end{array}$ & $\begin{array}{c}4.85 \times 10^{-3} \\
\pm 4.24 \times 10^{-4}\end{array}$ & $\begin{array}{c}4.93 \times 10^{-3} \\
\pm 4.49 \times 10^{-4}\end{array}$ & $\begin{array}{c}4.46 \times 10^{-3} \\
\pm 3.34 \times 10^{-4}\end{array}$ & $\begin{array}{c}4.15 \times 10^{-3} \\
\pm 3.69 \times 10^{-4}\end{array}$ & $\begin{array}{c}7.75 \times 10^{-3} \\
\pm 1.28 \times 10^{-3}\end{array}$ & $\begin{array}{c}3.27 \times 10^{-3} \\
\pm 4.72 \times 10^{-4}\end{array}$ \\
\hline 1320 & Graphite & A & 6 & 2450 & -1.38 & $\begin{array}{c}8.09 \times 10^{-5} \\
\pm 1.12 \times 10^{-4}\end{array}$ & $\begin{array}{c}1.89 \times 10^{-5} \\
\pm 9.66 \times 10^{-6}\end{array}$ & $\begin{array}{c}1.31 \times 10^{-5} \\
\pm 3.09 \times 10^{-6}\end{array}$ & $\begin{array}{c}9.36 \times 10^{-6} \\
\pm 1.85 \times 10^{-6}\end{array}$ & $\begin{array}{c}2.31 \times 10^{-5} \\
\pm 3.75 \times 10^{-6}\end{array}$ & & \\
\hline 1321 & Graphite & A & 6 & $2543^{*}$ & -2.67 & $\begin{array}{c}1.56 \times 10^{-4} \\
\pm 4.82 \times 10^{-6}\end{array}$ & $\begin{array}{c}2.21 \times 10^{-4} \\
\pm 7.30 \times 10^{-6}\end{array}$ & $\begin{array}{c}2.24 \times 10^{-4} \\
\pm 8.93 \times 10^{-6}\end{array}$ & $\begin{array}{c}2.29 \times 10^{-4} \\
\pm 1.25 \times 10^{-5}\end{array}$ & $\begin{array}{c}2.98 \times 10^{-4} \\
\pm 1.47 \times 10^{-5}\end{array}$ & & \\
\hline 1322 & Graphite & A & 6 & $2486^{*}$ & -3.16 & $\begin{array}{c}1.71 \times 10^{-4} \\
\pm 3.98 \times 10^{-6}\end{array}$ & $\begin{array}{c}3.10 \times 10^{-4} \\
\pm 3.33 \times 10^{-6}\end{array}$ & $\begin{array}{c}3.26 \times 10^{-4} \\
\pm 4.45 \times 10^{-6}\end{array}$ & $\begin{array}{c}3.54 \times 10^{-4} \\
\pm 5.58 \times 10^{-6}\end{array}$ & $\begin{array}{c}4.70 \times 10^{-4} \\
\pm 9.25 \times 10^{-6}\end{array}$ & & \\
\hline 1323 & Graphite & A & 6 & 2503 & -3.42 & $\begin{array}{c}3.27 \times 10^{-4} \\
\pm 1.15 \times 10^{-4} \\
\end{array}$ & $\begin{array}{c}5.11 \times 10^{-4} \\
\pm 1.09 \times 10^{-4} \\
\end{array}$ & $\begin{array}{c}6.04 \times 10^{-4} \\
\pm 1.03 \times 10^{-4} \\
\end{array}$ & $\begin{array}{c}6.55 \times 10^{-4} \\
\pm 8.62 \times 10^{-5} \\
\end{array}$ & $\begin{array}{c}7.65 \times 10^{-4} \\
\pm 1.22 \times 10^{-4} \\
\end{array}$ & & \\
\hline 1324 & Graphite & B & 6 & $2499^{*}$ & -0.82 & & & & $\begin{array}{c}4.86 \times 10^{-5} \\
\pm 3.71 \times 10^{-5} \\
\end{array}$ & $\begin{array}{c}7.60 \times 10^{-5} \\
\pm 4.17 \times 10^{-5} \\
\end{array}$ & $\begin{array}{c}7.45 \times 10^{-5} \\
\pm 5.94 \times 10^{-5} \\
\end{array}$ & $\begin{array}{c}6.97 \times 10^{-5} \\
\pm 2.12 \times 10^{-5} \\
\end{array}$ \\
\hline 1325 & Graphite & B & 6 & 2517 & -3.11 & & & & $\begin{array}{c}2.80 \times 10^{-5} \\
\pm 9.16 \times 10^{-6} \\
\end{array}$ & $\begin{array}{c}4.42 \times 10^{-5} \\
\pm 1.22 \times 10^{-5}\end{array}$ & $\begin{array}{c}5.54 \times 10^{-5} \\
\pm 1.07 \times 10^{-5} \\
\end{array}$ & $\begin{array}{r}4.34 \times 10^{-5} \\
\pm 3.68 \times 10^{-5} \\
\end{array}$ \\
\hline 1326 & Graphite & B & 6 & 2536 & -3.95 & & & & $\begin{array}{c}1.10 \times 10^{-3} \\
\pm 5.73 \times 10^{-5}\end{array}$ & $\begin{array}{c}1.37 \times 10^{-3} \\
\pm 1.12 \times 10^{-4}\end{array}$ & $\begin{array}{c}8.30 \times 10^{-4} \\
\pm 5.95 \times 10^{-5}\end{array}$ & $\begin{array}{c}1.02 \times 10^{-3} \\
\pm 1.37 \times 10^{-4}\end{array}$ \\
\hline 1327 & Graphite & B & 6 & 2519 & -3.46 & & & & $\begin{array}{c}1.88 \times 10^{-4} \\
\pm 1.73 \times 10^{-4}\end{array}$ & $\begin{array}{c}2.96 \times 10^{-4} \\
\pm 1.51 \times 10^{-4}\end{array}$ & $\begin{array}{c}1.71 \times 10^{-4} \\
\pm 1.27 \times 10^{-4}\end{array}$ & $\begin{array}{c}.21 \times 10^{-4} \\
\pm 4.06 \times 10^{-6}\end{array}$ \\
\hline
\end{tabular}


Table 2. Results of the multi-variable linear regression based on Equation 6 using experimental data from this study and those from literature listed in Appendix B. Twovariable parametrizations regressed the variables related to $\log f_{\mathrm{O}_{2}}(a)$, the metallic concentration of $\mathrm{S}(d)$, along with the equation constant (e). The $\mathrm{p}$-value for each variable used is also shown, with a significance level of $5 \%$.

\begin{tabular}{|ccccccccc|}
\hline Element & $\boldsymbol{N}^{\circ}$ & $\boldsymbol{R}^{2}$ & $\boldsymbol{a}$ & $p$-value & $\boldsymbol{d}$ & $p$-value & $\boldsymbol{e}$ & $p$-value \\
\hline $\mathbf{L a}$ & 25 & $\mathbf{0 . 8 6}$ & $-0.61 \pm 0.12$ & $1.90 .10^{-5}$ & $-14.20 \pm 1.5$ & $3.41 .10^{-9}$ & $-5.34 \pm 0.27$ & $2.90 .10^{-15}$ \\
$\mathbf{C e}$ & 24 & $\mathbf{0 . 8 7}$ & $-0.60 \pm 0.10$ & $6.66 .10^{-5}$ & $-13.45 \pm 1.40$ & $4.23 .10^{-9}$ & $-5.23 \pm 0.26$ & $4.37 .10^{-15}$ \\
$\mathbf{P r}$ & 21 & $\mathbf{0 . 8 8}$ & $-0.61 \pm 0.08$ & $6.50 .10^{-5}$ & $-12.65 \pm 1.30$ & $1.31 .10^{-8}$ & $-5.24 \pm 0.23$ & $1.63 .10^{-14}$ \\
$\mathbf{N d}$ & 42 & $\mathbf{0 . 8 1}$ & $-0.62 \pm 0.09$ & $7.00 .10^{-8}$ & $-12.45 \pm 1.16$ & $2.47 .10^{-13}$ & $-5.19 \pm 0.21$ & $5.17 .10^{-26}$ \\
$\mathbf{S m}$ & 42 & $\mathbf{0 . 8}$ & $-0.61 \pm 0.08$ & $5.14 .10^{-8}$ & $-11.91 \pm 1.17$ & $1.01 .10^{-12}$ & $-5.13 \pm 0.21$ & $9.24 .10^{-26}$ \\
$\mathbf{E u}$ & 25 & $\mathbf{0 . 9}$ & $-0.40 \pm 0.11$ & $9.64 .10^{-5}$ & $-15.12 \pm 1.24$ & $3.02 .10^{-11}$ & $-5.10 \pm 0.23$ & $1.30 .10^{-16}$ \\
$\mathbf{G d}$ & 20 & $\mathbf{0 . 8 9}$ & $-0.63 \pm 0.14$ & $3.82 .10^{-5}$ & $-11.59 \pm 1.17$ & $1.07 .10^{-8}$ & $-5.24 \pm 0.21$ & $2.43 .10^{-15}$ \\
\hline
\end{tabular}


Table 3. Concentration of REE ( $\mathrm{La}$ to $\mathrm{Gd}$ ), in ppb, along with the enrichment factor (EF) in RLE compared to CI for the BSE proposed in the literature, based on cosmochemichal and/or petrological approaches. All EF are taken from the original papers, with the exception of Allègre et al. (2001), for which the EF is calculated using REE concentrations in the BSE normalized to CI chondrite concentrations given by Barrat et al. (2012). Uncertainties on EF presented here are taken from the original papers for Palme and O'Neill (2014) and Lyubetskaya and Korenaga (2007), and extrapolated from the uncertainties on the REE concentrations given in the BSE in Allègre et al. (2001) and McDonough and Sun (1995). Uncertainty $(1 \sigma)$ on the enrichment factor takes into account the uncertainties on the BSE and the CI compositions.

\begin{tabular}{|ccccccccc|}
\hline & La & Ce & Pr & Nd & Sm & Eu & Gd & $\begin{array}{c}\text { EF compared } \\
\text { to CI }\end{array}$ \\
$\begin{array}{c}\text { Palme and } \\
\text { O'Neill, 2014 } \\
\text { Lyubetskaya } \\
\text { and Korenaga, } \\
\text { 2007 }\end{array}$ & $683 \pm 68$ & $1753 \pm 175$ & $265 \pm 39$ & $1341 \pm 134$ & $434 \pm 43$ & $166 \pm 17$ & $585 \pm 29$ & $\mathbf{2 . 8 3} \pm \mathbf{0 . 2 3}$ \\
$\begin{array}{c}\text { Allègre et al., } \\
\text { 2001 }\end{array}$ & $415 \pm 42$ & $1088 \pm 218$ & $165 \pm 8$ & $814 \pm 81$ & $259 \pm 8$ & $97.9 \pm 3$ & $348 \pm 28$ & $\mathbf{1 . 7 0} \pm \mathbf{0 . 2 4}$ \\
$\begin{array}{c}\text { McDonough } \\
\text { and Sun, 1995 }\end{array}$ & $648 \pm 65$ & $1675 \pm 168$ & $254 \pm 25$ & $1250 \pm 125$ & $406 \pm 41$ & $154 \pm 15$ & $544 \pm 54$ & $\mathbf{2 . 7 5} \pm \mathbf{0 . 2 7}$ \\
\hline
\end{tabular}


Table 4. Presentation of the accretion models considered in this study. a) Building block mixing proposed by several authors (in \%) in order to create the BSE nucleosynthetic composition, which also reproduce several elemental ratios of the BSE (see text for details). b) Resulting REE concentrations ( $\mathrm{ppb}$ ) in the BSE, along with their 1 sigma uncertainty. Where no precision relative to the chondritic subgroup is given, an average concentration of every subgroup is used to define the building block compositions. Concentrations used for chondrites are reported in Appendix E. Two enrichment factors based on these REE concentrations are reported for each model. EF is obtained using the measured composition of chondrites, whereas $\mathrm{EF}_{d r y}$ is based on chondritic compositions depleted in volatile elements to match the terrestrial depletion (see text for more details). The resulting enrichment factors are calculated for each REE based on the composition of CI chondrite given by Barrat et al. (2012). Uncertainty $(1 \sigma)$ on the enrichment factor takes into account the uncertainties on the calculated BSE and the CI composition.

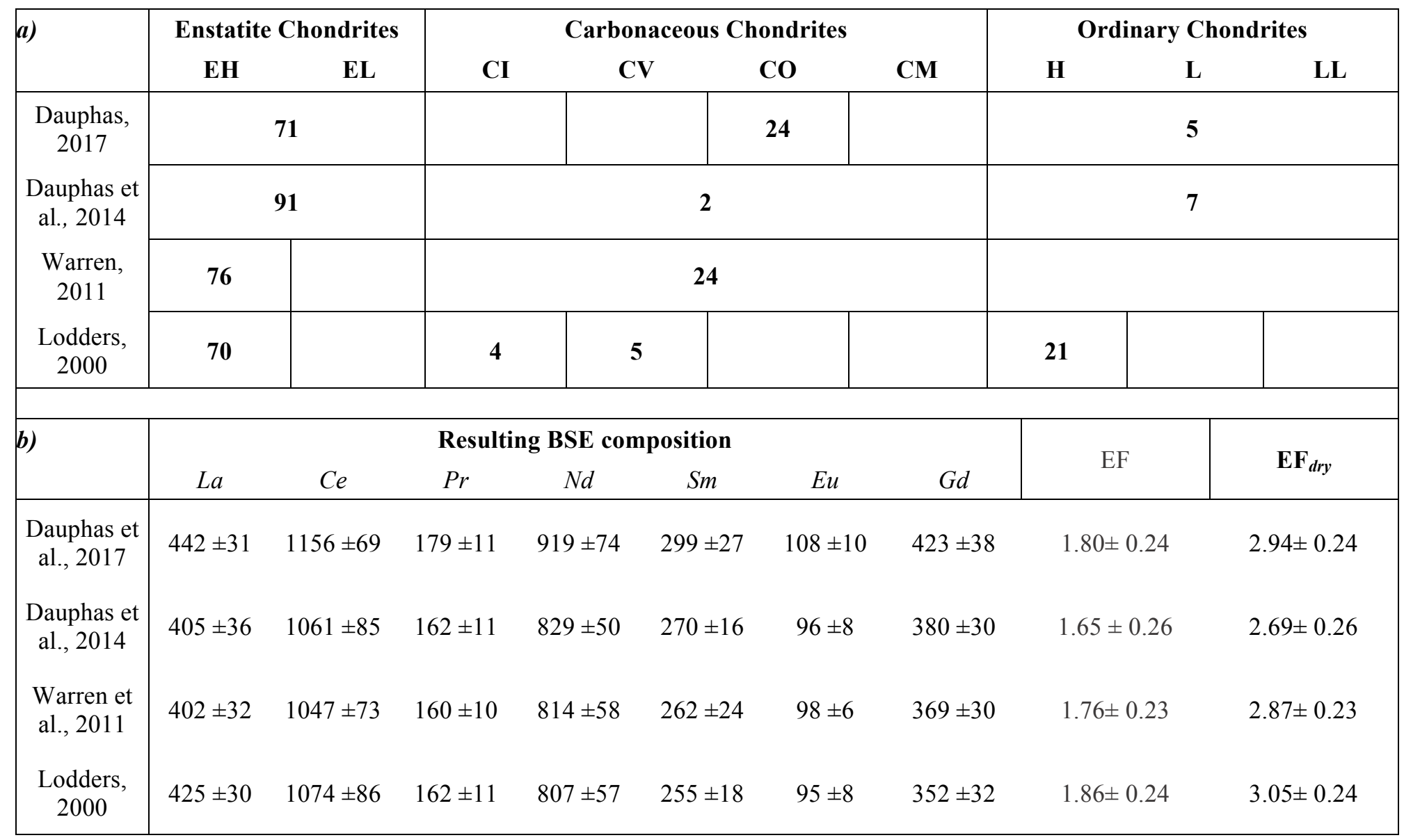


Figure 1 .

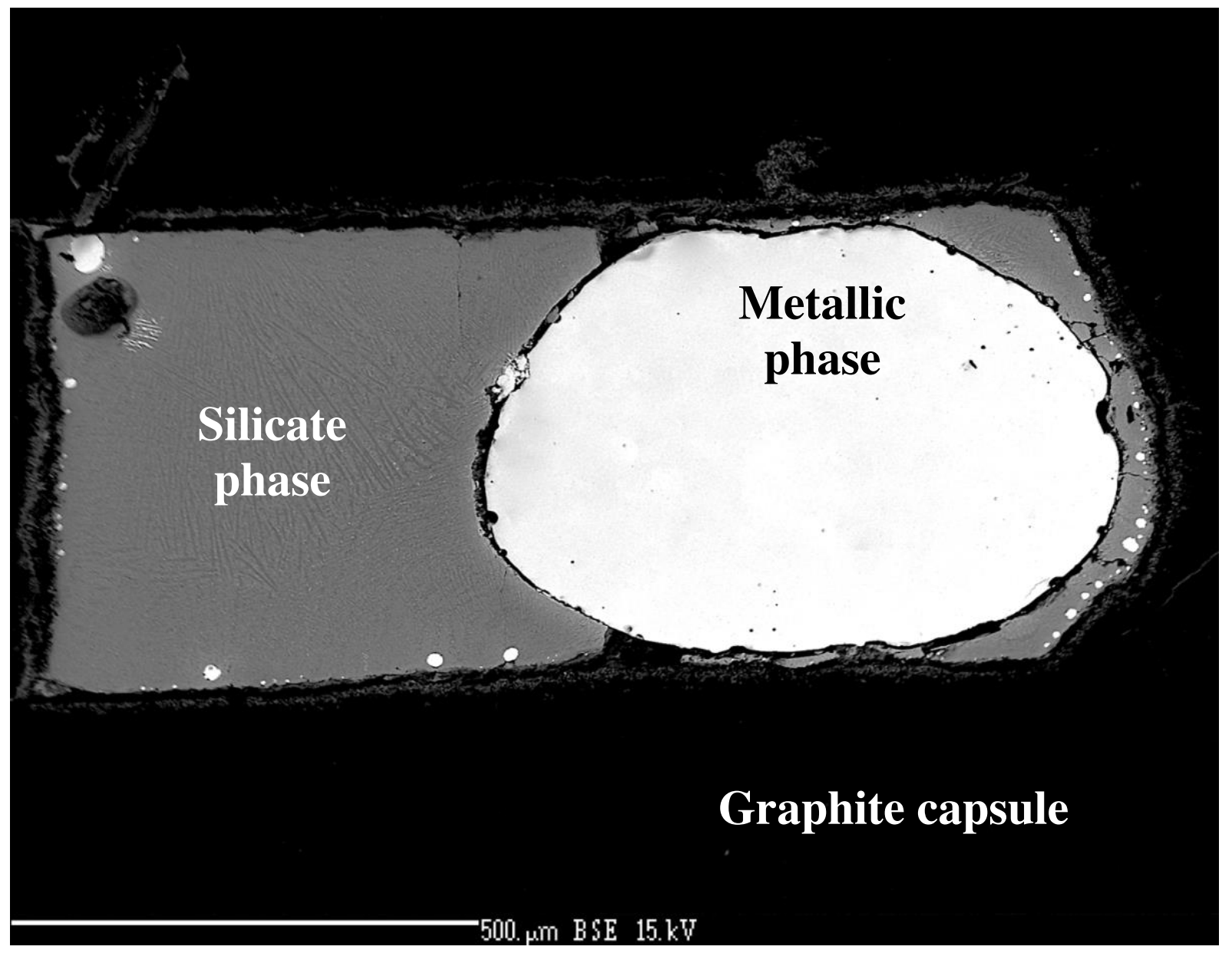

-500. $\mathrm{m}$ BSE $15 . \mathrm{kV}$ 
Figure 2 .
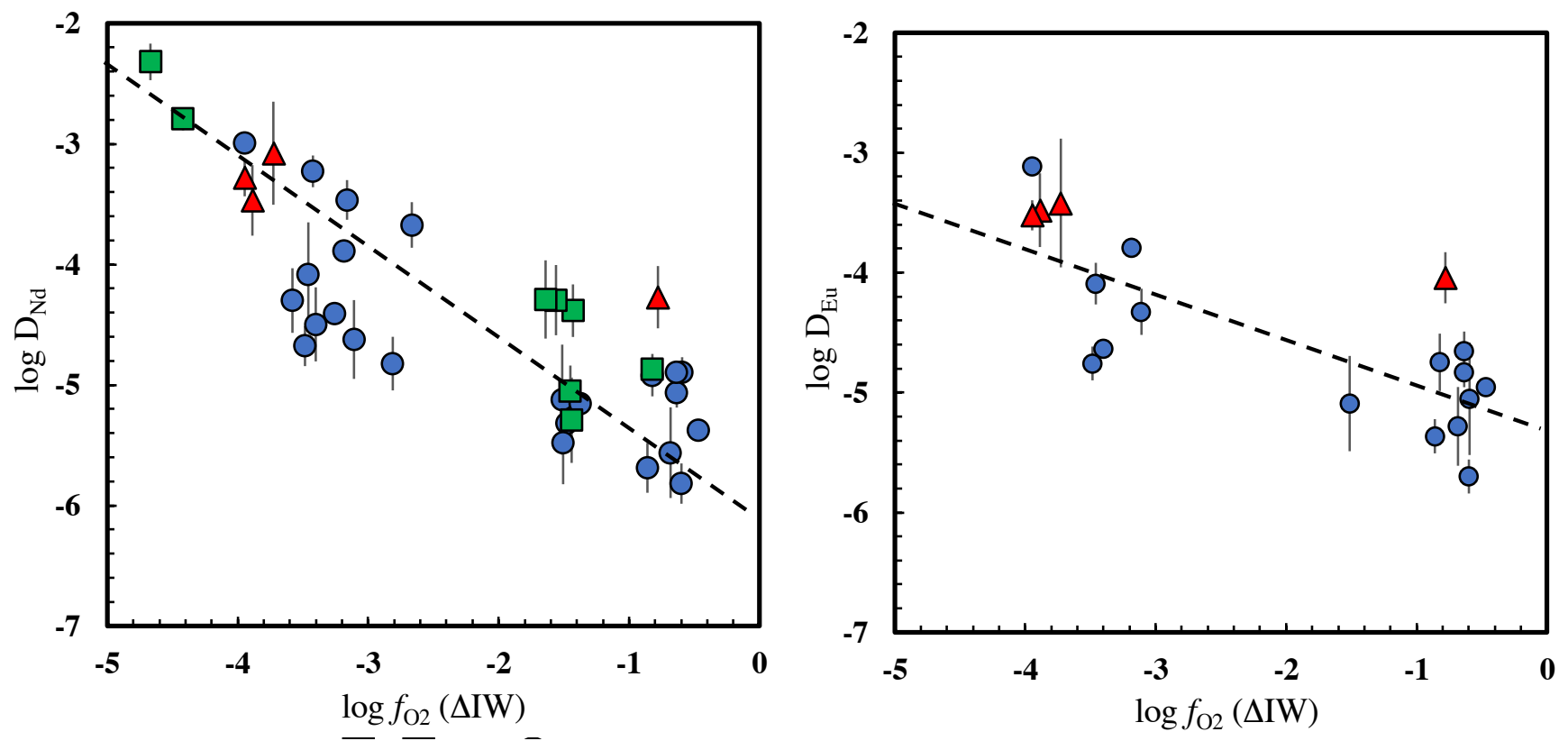

○ This study $\quad \Delta$ Wohlers \& Wood (2017)

$\square$ Bouhifd et al. (2015) 
Figure 3.

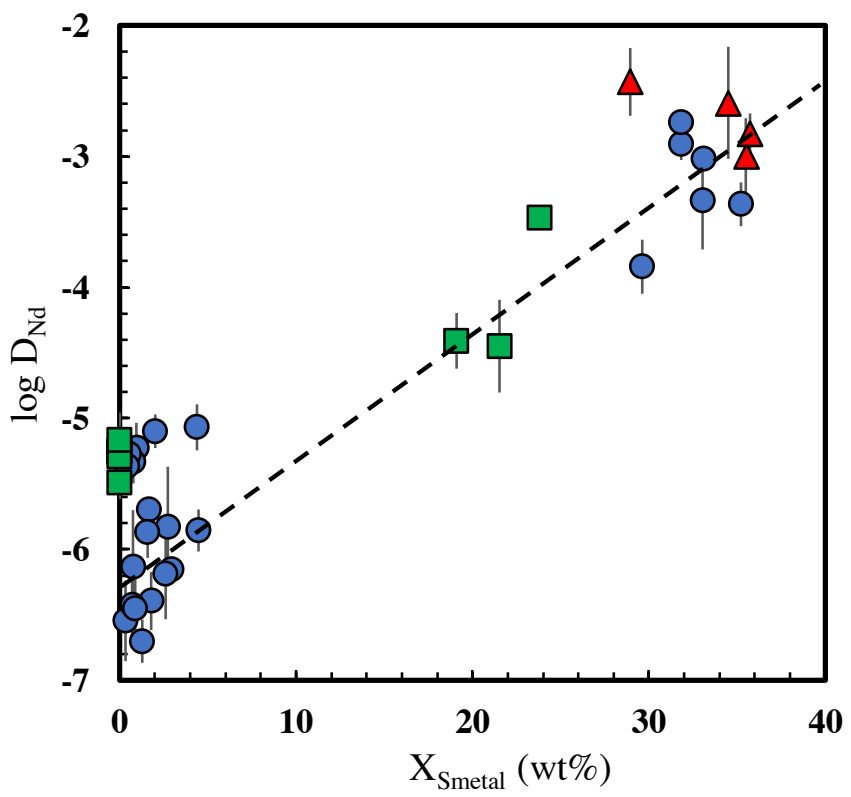

- This study

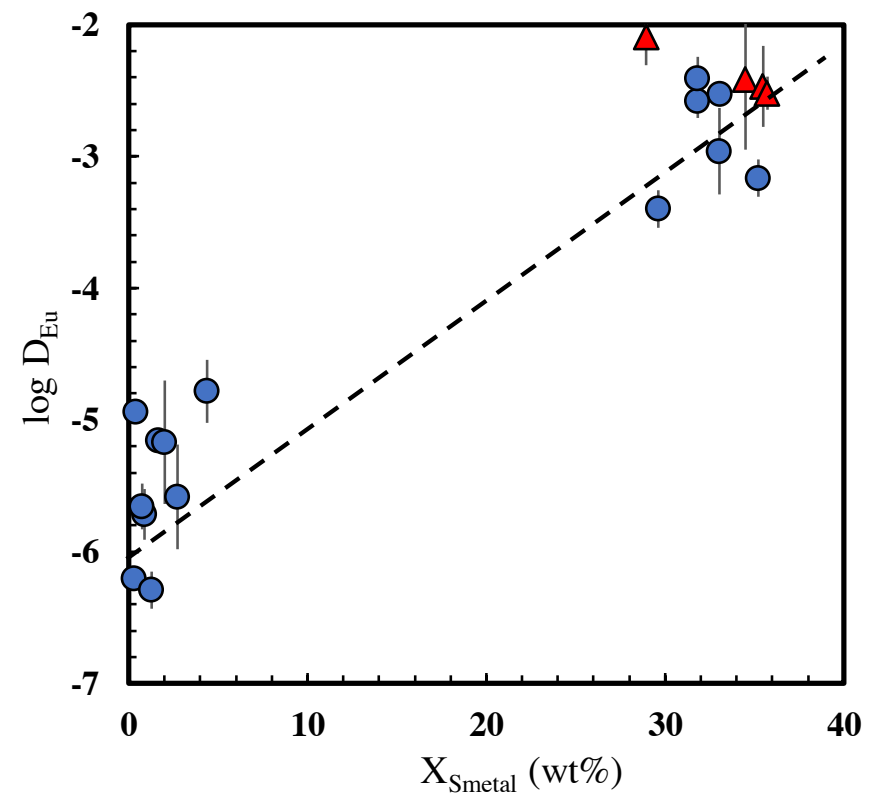

口 Bouhifd et al. (2015) 
Figure 4.

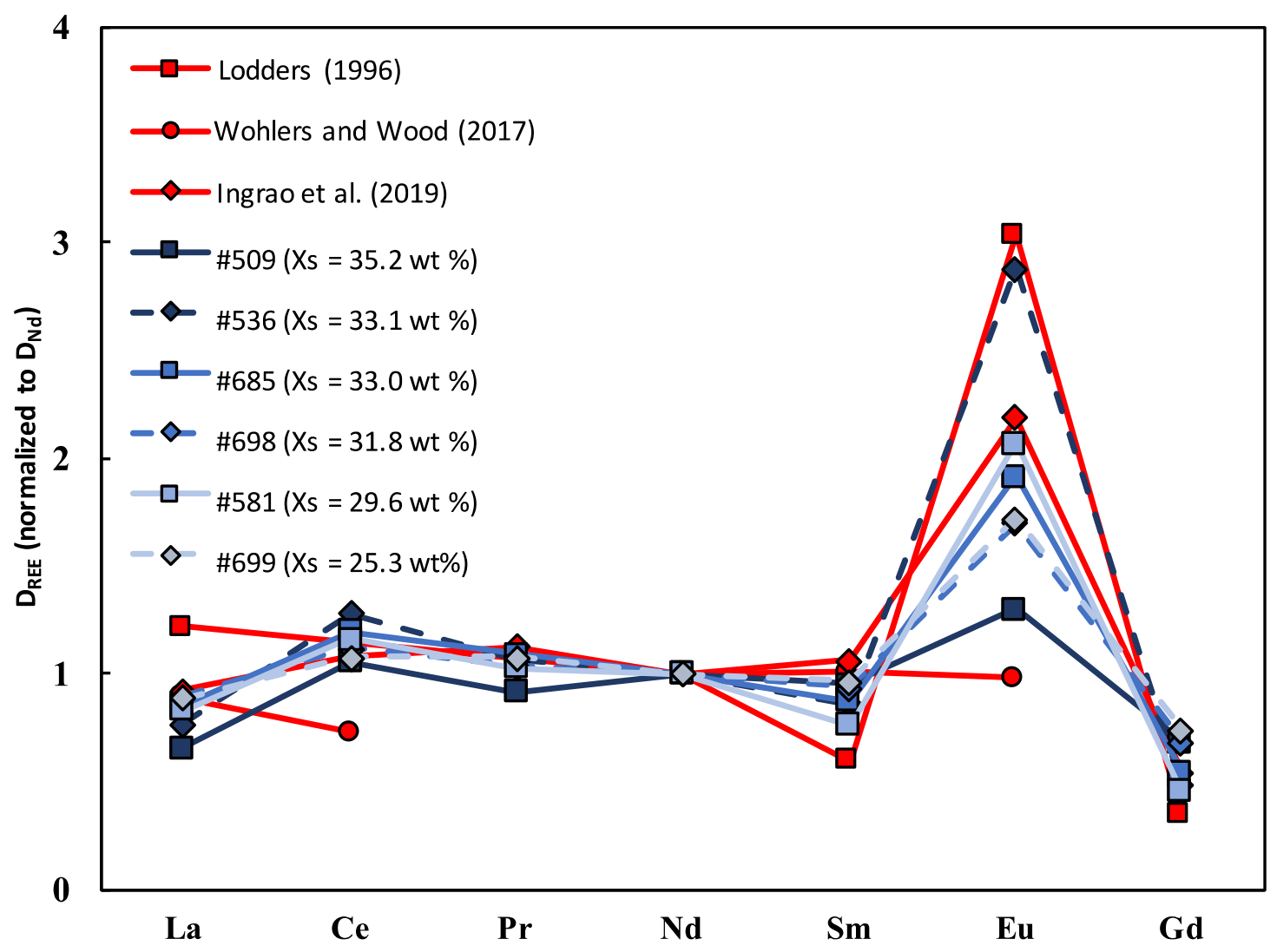


Figure 5.

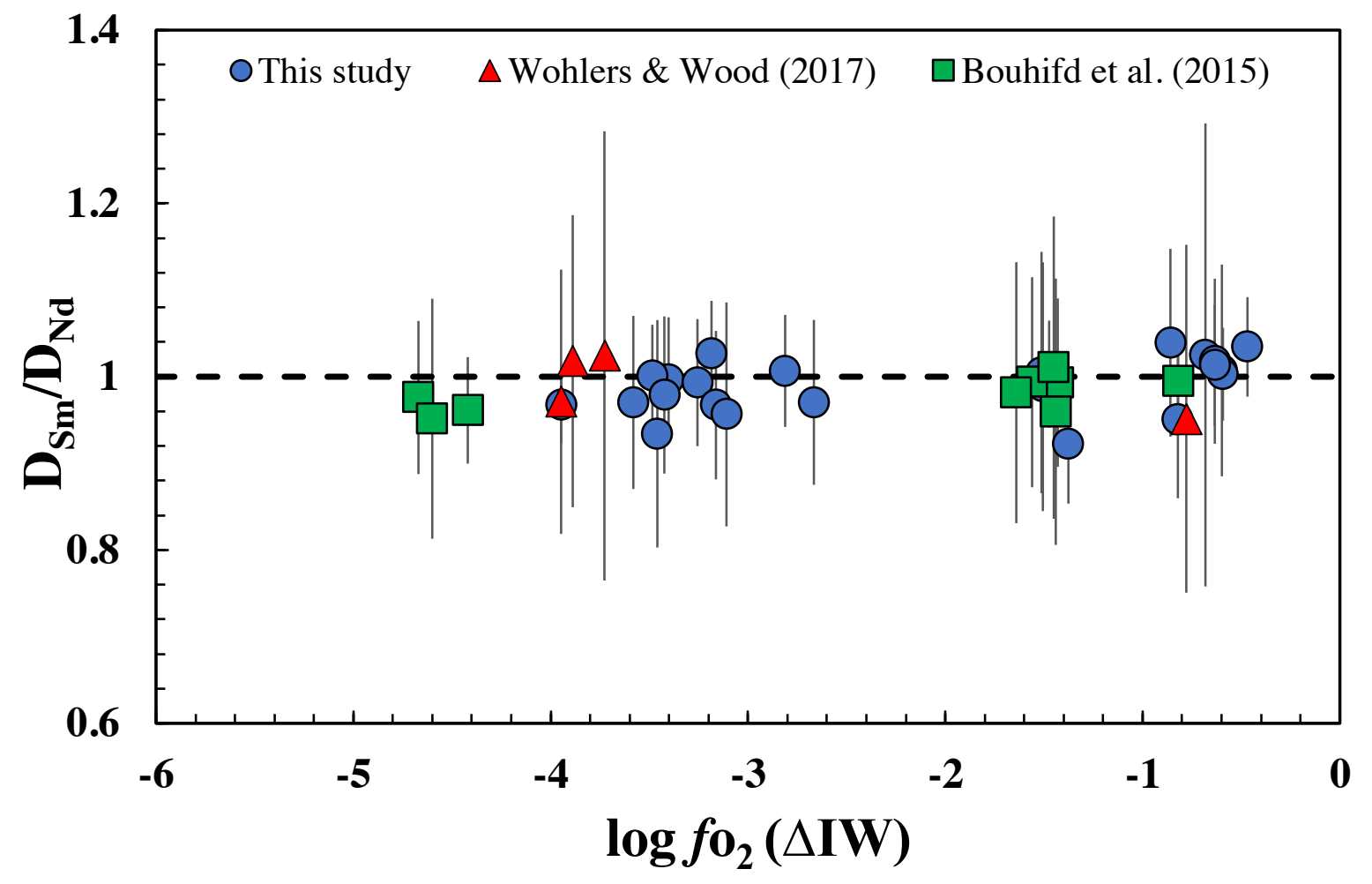


Figure 6.

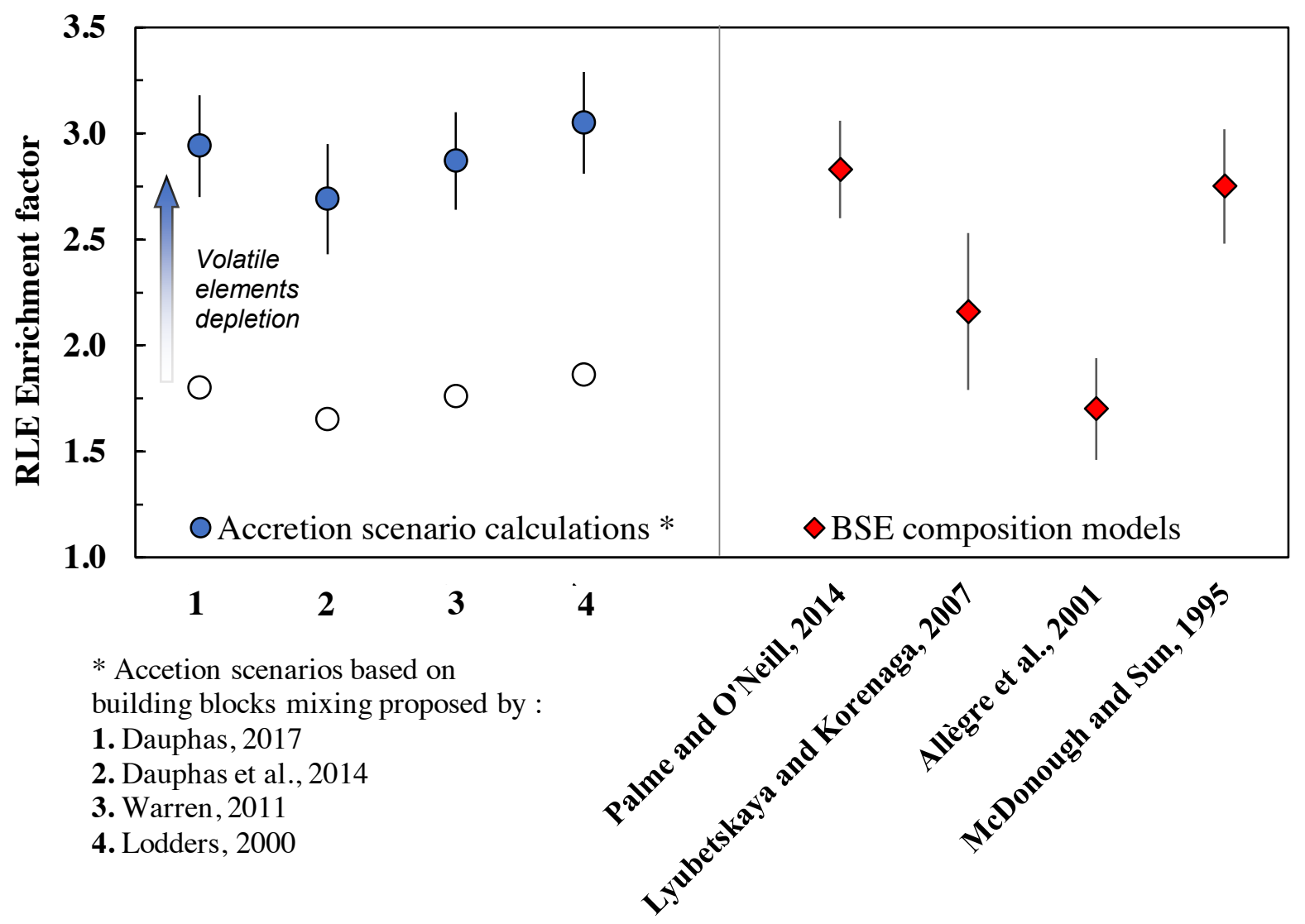


Appendix A1. Chemical analysis of all run products

\begin{tabular}{|c|c|c|c|c|c|c|c|c|c|c|c|c|c|c|c|c|c|c|c|c|c|c|c|c|}
\hline Run & 509 & 536 & 581 & 594 & 596 & 598 & 599 & 600 & 601 & 603 & 685 & 693 & 694 & 696 & 698 & 699 & 1320 & 1321 & 1322 & 1323 & 1324 & 1325 & 1326 & 1327 \\
\hline Capsule & $\mathrm{Gr}$ & Gr & $\mathrm{Gr}$ & $\mathrm{Gr}$ & $\mathrm{Gr}$ & $\mathrm{Gr}$ & $\mathrm{Gr}$ & $\mathrm{Gr}$ & Gr & Gr & $\mathrm{Gr}$ & $\mathrm{MgO}$ & $\mathrm{Gr}$ & $\mathrm{MgO}$ & $\mathrm{Gr}$ & Gr & Gr & $\mathrm{Gr}$ & $\mathrm{Gr}$ & $\mathrm{Gr}$ & $\mathrm{Gr}$ & $\mathrm{Gr}$ & $\mathrm{Gr}$ & $\mathrm{Gr}$ \\
\hline $\mathrm{P}$ (GPa) & 6 & 6 & 6 & 6 & 6 & 6 & 6 & 6 & 6 & 6 & 6 & 14 & 6 & 14 & 6 & 6 & 6 & 6 & 6 & 6 & 6 & 6 & 6 & 6 \\
\hline $\mathrm{T}(\mathrm{K})$ & 2361 & 2386 & 2563 & 2388 & 2499 & 2543 & 2532 & 2536 & 2517 & 2500 & 2529 & 2560 & 2365 & 2560 & 2429 & 2439 & 2450 & 2543 & 2486 & 2503 & 2499 & 2517 & 2536 & 2519 \\
\hline $\mathrm{NBO} / \mathrm{T}$ & 2.19 & 2.07 & 2.29 & 1.21 & 1.46 & 1.81 & 1.56 & 1.42 & 1.26 & 1.20 & 1.34 & 3.66 & 2.28 & 3.66 & 2.41 & 2.78 & 1.93 & 1.81 & 1.77 & 1.46 & 1.46 & 1.26 & 1.42 & 1.69 \\
\hline $\begin{array}{l}\text { Doping } \\
\text { solution }\end{array}$ & C & C & C & B & B & A & A & A & A & B & C & B & B & A & C & $\mathrm{C}$ & A & A & A & A & B & B & B & B \\
\hline \multicolumn{25}{|c|}{ Silicate major elements (wt\%) } \\
\hline $\mathrm{SiO}_{2}$ & $\begin{array}{l}43.15 \\
\pm 0.81\end{array}$ & $\begin{array}{l}38.59 \\
\pm 2.94\end{array}$ & $\begin{array}{l}44.83 \\
\pm 4.01\end{array}$ & $\begin{array}{l}64.22 \\
\pm 0.53\end{array}$ & $\begin{array}{l}65.66 \\
\pm 0.73\end{array}$ & $\begin{array}{l}55.91 \\
\pm 0.37\end{array}$ & $\begin{array}{l}62.52 \\
\pm 0.44\end{array}$ & $\begin{array}{l}66.54 \\
\pm 0.34\end{array}$ & $\begin{array}{l}64.42 \\
\pm 0.65\end{array}$ & $\begin{array}{l}63.72 \\
\pm 0.84\end{array}$ & $\begin{array}{l}46.31 \\
\pm 1.19\end{array}$ & $\begin{array}{l}40.50 \\
\pm 0.76\end{array}$ & $\begin{array}{l}46.33 \\
\pm 0.52\end{array}$ & $\begin{array}{l}40.73 \\
\pm 0.93\end{array}$ & $\begin{array}{l}45.95 \\
\pm 1.44\end{array}$ & $\begin{array}{l}39.77 \\
\pm 0.54\end{array}$ & $\begin{array}{l}55.24 \\
\pm 0.67\end{array}$ & $\begin{array}{l}62.45 \\
\pm 0.54\end{array}$ & $\begin{array}{l}58.28 \\
\pm 1.32\end{array}$ & $\begin{array}{l}63.06 \\
\pm 0.47\end{array}$ & $\begin{array}{l}50.13 \\
\pm 0.61\end{array}$ & $\begin{array}{c}64.58 \\
\pm 0.4\end{array}$ & $\begin{array}{l}64.93 \\
\pm 0.52\end{array}$ & $\begin{array}{l}62.22 \\
\pm 0.27\end{array}$ \\
\hline $\mathrm{Al}_{2} \mathrm{O}_{3}$ & $\begin{array}{c}2.10 \\
\pm 0.06\end{array}$ & $\begin{array}{c}1.63 \\
\pm 0.78\end{array}$ & $\begin{array}{c}3.08 \\
\pm 1.80\end{array}$ & $\begin{array}{c}4.93 \\
\pm 0.09\end{array}$ & $\begin{array}{c}2.84 \\
\pm 0.07\end{array}$ & $\begin{array}{c}2.30 \\
\pm 0.07\end{array}$ & $\begin{array}{c}2.23 \\
\pm 0.08\end{array}$ & $\begin{array}{c}2.32 \\
\pm 0.11\end{array}$ & $\begin{array}{c}2.37 \\
\pm 0.23\end{array}$ & $\begin{array}{c}2.56 \\
\pm 0.20\end{array}$ & $\begin{array}{c}2.02 \\
\pm 0.05\end{array}$ & $\begin{array}{c}0.69 \\
\pm 0.25\end{array}$ & $\begin{array}{l}2.01 \\
\pm 0.09\end{array}$ & $\begin{array}{c}0.86 \\
\pm 0.23\end{array}$ & $\begin{array}{c}2.05 \\
\pm 0.23\end{array}$ & $\begin{array}{c}1.93 \\
\pm 0.09\end{array}$ & $\begin{array}{c}1.8 \\
\pm 0.15\end{array}$ & $\begin{array}{c}2.02 \\
\pm 0.05\end{array}$ & $\begin{array}{c}4.07 \\
\pm 0.86\end{array}$ & $\begin{array}{c}2.07 \\
\pm 0.06\end{array}$ & $\begin{array}{c}2.12 \\
\pm 0.08\end{array}$ & $\begin{array}{c}2.55 \\
\pm 0.05\end{array}$ & $\begin{array}{c}2.61 \\
\pm 0.05\end{array}$ & $\begin{array}{c}1.84 \\
\pm 0.02\end{array}$ \\
\hline $\mathrm{FeO}$ & $\begin{array}{l}29.60 \\
\pm 0.62\end{array}$ & $\begin{array}{r}33.79 \\
\pm 5.14\end{array}$ & $\begin{array}{l}24.20 \\
\pm 3.61\end{array}$ & $\begin{array}{c}0.93 \\
\pm 0.60\end{array}$ & $\begin{array}{c}0.43 \\
\pm 0.36\end{array}$ & $\begin{array}{c}6.05 \\
\pm 0.30\end{array}$ & $\begin{array}{c}0.89 \\
\pm 0.13\end{array}$ & $\begin{array}{c}1.31 \\
\pm 0.68\end{array}$ & $\begin{array}{c}0.41 \\
\pm 0.12\end{array}$ & $\begin{array}{c}0.64 \\
\pm 0.08\end{array}$ & $\begin{array}{l}21.16 \\
\pm 1.62\end{array}$ & $\begin{array}{c}7.77 \\
\pm 0.57\end{array}$ & $\begin{array}{r}20.39 \\
+0.6\end{array}$ & $\begin{array}{c}7.92 \\
\pm 0.77\end{array}$ & $\begin{array}{r}22.98 \\
+1.89\end{array}$ & $\begin{array}{l}31.25 \\
+0.63\end{array}$ & $\begin{array}{l}8.08 \\
+0.8\end{array}$ & $\begin{array}{c}1.77 \\
+0.85\end{array}$ & $\begin{array}{c}0.96 \\
+0.33\end{array}$ & $\begin{array}{c}0.60 \\
+0.34\end{array}$ & $\begin{array}{l}13.60 \\
\pm 0.93\end{array}$ & $\begin{array}{l}1.03 \\
+01\end{array}$ & $\begin{array}{c}0.28 \\
\pm 0.12\end{array}$ & $\begin{array}{l}0.59 \\
\pm 0.1\end{array}$ \\
\hline $\mathrm{MnO}$ & $\begin{array}{c}0.14 \\
\pm 0.01\end{array}$ & $\begin{array}{c}0.20 \\
\pm 0.06\end{array}$ & $\begin{array}{c}0.19 \\
\pm 0.01\end{array}$ & $\begin{array}{c}0.17 \\
\pm 0.03\end{array}$ & $\begin{array}{c}0.06 \\
\pm 0.04\end{array}$ & $\begin{array}{c}0.27 \\
\pm 0.02\end{array}$ & $\begin{array}{c}0.12 \\
\pm 0.01\end{array}$ & $\begin{array}{c}0.06 \\
\pm 0.02\end{array}$ & $\begin{array}{c}0.09 \\
\pm 0.04\end{array}$ & $\begin{array}{c}0.04 \\
\pm 0.04\end{array}$ & $\begin{array}{c}0.18 \\
\pm 0.02\end{array}$ & $\begin{array}{c}0.04 \\
\pm 0.02\end{array}$ & $\begin{array}{c}0.12 \\
\pm 0.03\end{array}$ & $\begin{array}{c}0.01 \\
\pm 0.01\end{array}$ & $\begin{array}{c}0.18 \\
\pm 0.03\end{array}$ & $\begin{array}{c}0.16 \\
\pm 0.02\end{array}$ & $\begin{array}{c}0.10 \\
\pm 0.03\end{array}$ & $\begin{array}{c}0.02 \\
\pm 0.02\end{array}$ & $\begin{array}{c}0.03 \\
\pm 0.01\end{array}$ & $\begin{array}{c}0.03 \\
\pm 0.02\end{array}$ & $\begin{array}{c}0.08 \\
\pm 0.05\end{array}$ & $\begin{array}{c}0.02 \\
\pm 0.02\end{array}$ & $\begin{array}{c}0.04 \\
\pm 0.03\end{array}$ & $\begin{array}{c}0.06 \\
\pm 0.03\end{array}$ \\
\hline $\mathrm{MgO}$ & $\begin{array}{l}23.82 \\
\pm 0.61\end{array}$ & $\begin{array}{l}24.27 \\
\pm 1.92\end{array}$ & $\begin{array}{l}20.89 \\
\pm 6.35\end{array}$ & $\begin{array}{l}23.89 \\
\pm 0.32\end{array}$ & $\begin{array}{l}31.11 \\
\pm 0.68\end{array}$ & $\begin{array}{l}30.22 \\
\pm 0.46\end{array}$ & $\begin{array}{l}31.52 \\
\pm 0.44\end{array}$ & $\begin{array}{l}25.92 \\
\pm 1.75\end{array}$ & $\begin{array}{l}31.46 \\
\pm 1.87\end{array}$ & $\begin{array}{l}24.16 \\
\pm 2.02\end{array}$ & $\begin{array}{l}24.59 \\
\pm 0.48\end{array}$ & $\begin{array}{l}45.67 \\
\pm 2.04\end{array}$ & $\begin{array}{l}23.87 \\
\pm 0.32\end{array}$ & $\begin{array}{l}45.37 \\
\pm 1.84\end{array}$ & $\begin{array}{l}23.78 \\
\pm 0.52\end{array}$ & $\begin{array}{l}19.99 \\
\pm 0.65\end{array}$ & $\begin{array}{l}30.93 \\
\pm 1.01\end{array}$ & $\begin{array}{l}29.08 \\
\pm 0.15\end{array}$ & $\begin{array}{l}34.37 \\
\pm 0.34\end{array}$ & $\begin{array}{l}29.62 \\
\pm 0.34\end{array}$ & $\begin{array}{l}27.77 \\
\pm 0.17\end{array}$ & $\begin{array}{c}25.67 \\
\pm 0.4\end{array}$ & $\begin{array}{l}29.47 \\
\pm 0.34\end{array}$ & $\begin{array}{c}34.3 \\
\pm 0.20\end{array}$ \\
\hline $\mathrm{CaO}$ & $\begin{array}{c}1.18 \\
\pm 0.11\end{array}$ & $\begin{array}{c}1.40 \\
\pm 0.69\end{array}$ & $\begin{array}{c}2.20 \\
\pm 1.94\end{array}$ & $\begin{array}{c}2.85 \\
\pm 0.09\end{array}$ & $\begin{array}{c}1.71 \\
\pm 0.14\end{array}$ & $\begin{array}{c}1.63 \\
\pm 0.06\end{array}$ & $\begin{array}{c}1.74 \\
\pm 0.08\end{array}$ & $\begin{array}{l}1.31 \\
\pm 0.3\end{array}$ & $\begin{array}{c}1.35 \\
\pm 0.14\end{array}$ & $\begin{array}{c}1.97 \\
\pm 0.17\end{array}$ & $\begin{array}{c}1.46 \\
\pm 0.19\end{array}$ & $\begin{array}{c}1.02 \\
\pm 0.45\end{array}$ & $\begin{array}{c}1.55 \\
\pm 0.09\end{array}$ & $\begin{array}{c}1.51 \\
\pm 0.58\end{array}$ & $\begin{array}{l}1.60 \\
\pm 0.25\end{array}$ & $\begin{array}{c}1.28 \\
\pm 0.11\end{array}$ & $\begin{array}{c}1.37 \\
\pm 0.11\end{array}$ & $\begin{array}{c}1.59 \\
\pm 0.04\end{array}$ & $\begin{array}{c}1.19 \\
\pm 0.08\end{array}$ & $\begin{array}{c}1.68 \\
\pm 0.05\end{array}$ & $\begin{array}{c}1.74 \\
\pm 0.08\end{array}$ & $\begin{array}{c}1.87 \\
\pm 0.02\end{array}$ & $\begin{array}{c}2.35 \\
\pm 0.12\end{array}$ & $\begin{array}{c}1.44 \\
\pm 0.07\end{array}$ \\
\hline $\mathrm{NiO}$ & $\begin{array}{c}0.01 \\
\pm 0.01\end{array}$ & $\begin{array}{c}0.13 \\
\pm 0.07\end{array}$ & $\begin{array}{c}0.03 \\
\pm 0.04\end{array}$ & $\begin{array}{c}0.05 \\
\pm 0.03\end{array}$ & $\begin{array}{c}0.01 \\
\pm 0.02\end{array}$ & $\begin{array}{c}0.11 \\
\pm 0.09\end{array}$ & $0 \pm 0$ & $\begin{array}{c}0.03 \\
\pm 0.04\end{array}$ & $\begin{array}{c}0.01 \\
\pm 0.01\end{array}$ & $\begin{array}{c}0.10 \\
\pm 0.04\end{array}$ & $\begin{array}{c}0.02 \\
\pm 0.02\end{array}$ & $\begin{array}{c}0.12 \\
\pm 0.02\end{array}$ & $\begin{array}{c}0.05 \\
\pm 0.03\end{array}$ & $\begin{array}{c}0.11 \\
\pm 0.03\end{array}$ & $\begin{array}{c}0.03 \\
\pm 0.04\end{array}$ & $\begin{array}{c}0.02 \\
\pm 0.03\end{array}$ & $\begin{array}{c}0.03 \\
\pm 0.03\end{array}$ & $\begin{array}{c}0.00 \\
\pm 0.00\end{array}$ & $\begin{array}{c}0.01 \\
\pm 0.02\end{array}$ & $\begin{array}{c}0.00 \\
\pm 0.00\end{array}$ & $\begin{array}{c}0.09 \\
\pm 0.02\end{array}$ & $\begin{array}{c}0.06 \\
\pm 0.02\end{array}$ & $\begin{array}{c}0.03 \\
\pm 0.02\end{array}$ & $\begin{array}{c}0.01 \\
\pm 0.01\end{array}$ \\
\hline $\mathrm{s}$ & $\begin{array}{c}0,44 \\
\pm 0,17\end{array}$ & $\begin{array}{c}0,41 \\
\pm 0,42\end{array}$ & $\begin{array}{c}0,39 \\
\pm 0,34\end{array}$ & $\begin{array}{c}0,85 \\
\pm 0,02\end{array}$ & $\begin{array}{c}2,35 \\
\pm 0,18\end{array}$ & $\begin{array}{c}0,09 \\
\pm 0,01\end{array}$ & $\begin{array}{c}0,58 \\
\pm 0,05\end{array}$ & $\begin{array}{c}0,69 \\
\pm 0,09\end{array}$ & $\begin{array}{l}1,88 \\
\pm 0,35\end{array}$ & $\begin{array}{c}0,52 \\
\pm 0,12\end{array}$ & $\begin{array}{c}0,58 \\
\pm 0,23\end{array}$ & $\begin{array}{c}0,02 \\
\pm 0,02\end{array}$ & $\begin{array}{c}0,06 \\
\pm 0,02\end{array}$ & $\begin{array}{c}0,04 \\
\pm 0,03\end{array}$ & $\begin{array}{c}0,46 \\
\pm 0,10\end{array}$ & $\begin{array}{c}0,32 \\
\pm 0,04\end{array}$ & $\begin{array}{c}0,12 \\
\pm 0,03\end{array}$ & $\begin{array}{c}0,58 \\
\pm 0,03\end{array}$ & $\begin{array}{c}0,40 \\
\pm 0,04\end{array}$ & $\begin{array}{c}0,69 \\
\pm 0,01\end{array}$ & $\begin{array}{c}0,08 \\
\pm 0,02\end{array}$ & $\begin{array}{c}0,91 \\
\pm 0,04\end{array}$ & $\begin{array}{c}1,74 \\
\pm 0,07\end{array}$ & $\begin{array}{c}0,82 \\
\pm 0,04\end{array}$ \\
\hline Total & $\begin{array}{c}100 \\
\pm 0.41\end{array}$ & $\begin{array}{c}100 \\
\pm 0.25\end{array}$ & $\begin{array}{l}95.41 \\
\pm 3.60\end{array}$ & $\begin{array}{l}97.05 \\
\pm 0.23\end{array}$ & $\begin{array}{l}101.81 \\
\pm 0.58\end{array}$ & $\begin{array}{l}96.48 \\
\pm 0.60\end{array}$ & $\begin{array}{l}99.02 \\
\pm 0.96\end{array}$ & $\begin{array}{l}97.49 \\
\pm 0.96\end{array}$ & $\begin{array}{l}100.1 \\
\pm 0.56\end{array}$ & $\begin{array}{l}93.21 \\
\pm 1.57\end{array}$ & $\begin{array}{l}95.75 \\
\pm 1.11\end{array}$ & $\begin{array}{l}95.81 \\
\pm 1.17\end{array}$ & $\begin{array}{l}94.32 \\
\pm 0.23\end{array}$ & $\begin{array}{l}96.51 \\
\pm 0.7\end{array}$ & $\begin{array}{l}95.87 \\
\pm 0.76\end{array}$ & $\begin{array}{l}94.98 \\
\pm 0.62\end{array}$ & $\begin{array}{l}97.55 \\
\pm 0.86\end{array}$ & $\begin{array}{l}96.94 \\
\pm 0.39\end{array}$ & $\begin{array}{l}98.92 \\
\pm 0.93\end{array}$ & $\begin{array}{l}97.06 \\
\pm 0.82\end{array}$ & $\begin{array}{l}95.53 \\
\pm 0.49\end{array}$ & $\begin{array}{l}95.79 \\
\pm 0.63\end{array}$ & $\begin{array}{l}99.71 \\
\pm 0.85\end{array}$ & $\begin{array}{l}100.5 \\
\pm 0.28\end{array}$ \\
\hline \multicolumn{25}{|c|}{ Silicate trace elements (ppm) } \\
\hline $\mathrm{La}$ & $\begin{array}{l}1488.76 \\
\pm 162.88\end{array}$ & $\begin{array}{l}1115.2 \\
\pm 15.96\end{array}$ & $\begin{array}{c}2210.36 \\
\pm 160.5\end{array}$ & n.d. & n.d. & $\begin{array}{c}1683.49 \\
\pm 59.41\end{array}$ & $\begin{array}{l}1773.03 \\
\pm 11.19\end{array}$ & $\begin{array}{l}1825.08 \\
\pm 120.95\end{array}$ & $\begin{array}{l}904.13 \\
\pm 56.85\end{array}$ & n.d. & $\begin{array}{l}1432.74 \\
\pm 52.85\end{array}$ & n.d. & n.d. & $\begin{array}{l}5573.63 \\
\pm 703.63\end{array}$ & $\begin{array}{l}1438.02 \\
\pm 60.84\end{array}$ & $\begin{array}{l}1440.28 \\
\pm 60.84\end{array}$ & $\begin{array}{l}2950.63 \\
\pm 382.65\end{array}$ & $\begin{array}{c}4099 \\
\pm 126.62\end{array}$ & $\begin{array}{l}1728.8 \\
\pm 40.32\end{array}$ & $\begin{array}{l}3501.33 \\
\pm 42.93\end{array}$ & n.d. & n.d. & n.d. & n.d. \\
\hline $\mathrm{Ce}$ & $\begin{array}{l}1466.95 \\
\pm 158.71\end{array}$ & $\begin{array}{l}1116.8 \\
\pm 32.4\end{array}$ & $\begin{array}{l}2241.21 \\
\pm 134.72\end{array}$ & n.d. & n.d. & $\begin{array}{l}1935.38 \\
\pm 64.47\end{array}$ & $\begin{array}{l}1817.6 \\
\pm 14.27\end{array}$ & $\begin{array}{l}1922.86 \\
\pm 158.84\end{array}$ & $\begin{array}{l}960.16 \\
\pm 68.11\end{array}$ & n.d. & $\begin{array}{l}1442.32 \\
\pm 34.31\end{array}$ & n.d. & n.d. & $\begin{array}{r}5000.36 \\
\pm 569.46\end{array}$ & $\begin{array}{c}1438.83 \\
\pm 69\end{array}$ & $\begin{array}{c}1440.22 \\
\pm 69\end{array}$ & $\begin{array}{c}3207.3 \\
\pm 437.94\end{array}$ & $\begin{array}{l}4060.12 \\
\pm 133.97\end{array}$ & $\begin{array}{l}1847.67 \\
\pm 19.85\end{array}$ & $\begin{array}{c}3590.89 \\
\pm 29.12\end{array}$ & n.d. & n.d. & n.d. & n.d. \\
\hline $\operatorname{Pr}$ & $\begin{array}{l}1380.46 \\
\pm 152.28\end{array}$ & $\begin{array}{c}1092.65 \\
\pm 8.24\end{array}$ & $\begin{array}{l}2142.67 \\
\pm 133.15\end{array}$ & n.d. & n.d. & $\begin{array}{c}1969.17 \\
\pm 94.86\end{array}$ & $\begin{array}{c}1818.56 \\
\pm 16.18\end{array}$ & $\begin{array}{l}1885.15 \\
\pm 134.56\end{array}$ & $\begin{array}{l}951.79 \\
\pm 78.97\end{array}$ & n.d. & $\begin{array}{l}1400.6 \\
\pm 29.99\end{array}$ & n.d. & n.d. & $\begin{array}{c}5023.98 \\
\pm 488.6\end{array}$ & $\begin{array}{l}1413.92 \\
\pm 72.87\end{array}$ & $\begin{array}{c}1410.02 \\
\pm 72.87\end{array}$ & $\begin{array}{l}3106.54 \\
\pm 435.34\end{array}$ & $\begin{array}{l}3912.61 \\
\pm 155.66\end{array}$ & $\begin{array}{l}1824.01 \\
\pm 24.87\end{array}$ & $\begin{array}{c}3486.91 \\
\pm 17.36\end{array}$ & n.d. & n.d. & n.d. & n.d. \\
\hline $\mathrm{Nd}$ & $\begin{array}{c}1397.98 \\
\pm 162.8\end{array}$ & $\begin{array}{l}1106.2 \\
\pm 1.24\end{array}$ & $\begin{array}{l}2341.73 \\
\pm 129.97\end{array}$ & $\begin{array}{l}4846.55 \\
\pm 167.12\end{array}$ & $\begin{array}{c}1306.93 \\
\pm 12.94\end{array}$ & $\begin{array}{l}1939.57 \\
\pm 31.71\end{array}$ & $\begin{array}{l}1778.71 \\
\pm 16.68\end{array}$ & $\begin{array}{c}1883.78 \\
\pm 138\end{array}$ & $\begin{array}{l}946.77 \\
\pm 71.77\end{array}$ & $\begin{array}{l}11009.18 \\
\pm 529.81\end{array}$ & $\begin{array}{l}1414.77 \\
\pm 35.77\end{array}$ & $\begin{array}{l}4097.52 \\
\pm 319.91\end{array}$ & $\begin{array}{l}6795.43 \\
\pm 70.15\end{array}$ & $\begin{array}{l}5190.93 \\
\pm 494.6\end{array}$ & $\begin{array}{l}1456.72 \\
\pm 66.23\end{array}$ & $\begin{array}{l}1459.12 \\
\pm 66.23\end{array}$ & $\begin{array}{l}3171.43 \\
\pm 476.81\end{array}$ & $\begin{array}{l}4157.83 \\
\pm 227.23\end{array}$ & $\begin{array}{l}1803.75 \\
\pm 28.45\end{array}$ & $\begin{array}{c}3662.92 \\
\pm 12.08\end{array}$ & $\begin{array}{l}5352.93 \\
\pm 481.7\end{array}$ & $\begin{array}{c}8585.13 \\
\pm 85.86\end{array}$ & $\begin{array}{l}3676.36 \\
\pm 37.35\end{array}$ & $\begin{array}{l}543.56 \\
\pm 5.34\end{array}$ \\
\hline $\mathrm{Sm}$ & $\begin{array}{l}1398.14 \\
\pm 169.83\end{array}$ & $\begin{array}{c}1180.27 \\
\pm 20.09\end{array}$ & $\begin{array}{l}2423.93 \\
\pm 137.62\end{array}$ & $\begin{array}{c}5176.65 \\
\pm 136.5\end{array}$ & $\begin{array}{l}1377.22 \\
\pm 12.02\end{array}$ & $\begin{array}{c}2386.39 \\
\pm 29.39\end{array}$ & $\begin{array}{c}1811.96 \\
\pm 3.45\end{array}$ & $\begin{array}{c}1976.1 \\
\pm 147.96\end{array}$ & $\begin{array}{l}1006.88 \\
\pm 75.83\end{array}$ & $\begin{array}{c}10715.86 \\
\pm 584.18\end{array}$ & & $\begin{array}{l}4246.38 \\
\pm 196.01\end{array}$ & $\begin{array}{c}6734.14 \\
\pm 43.76\end{array}$ & $\begin{array}{l}5368.81 \\
\pm 422.37\end{array}$ & $\begin{array}{c}1505.86 \\
\pm 65.63\end{array}$ & $\begin{array}{c}1503.46 \\
\pm 65.63\end{array}$ & $\begin{array}{l}3598.06 \\
\pm 466.16\end{array}$ & $\begin{array}{c}3999.4 \\
\pm 197.66\end{array}$ & $\begin{array}{c}1840.75 \\
\pm 36.19\end{array}$ & $\begin{array}{c}3700.39 \\
\pm 7.89\end{array}$ & $\begin{array}{l}5416.94 \\
\pm 447.91\end{array}$ & $\begin{array}{c}8424.43 \\
\pm 54.29\end{array}$ & $\begin{array}{c}3858.79 \\
\pm 31.17\end{array}$ & $\begin{array}{c}578.14 \\
\pm 3.3\end{array}$ \\
\hline Eu & $\begin{array}{l}1385.91 \\
\pm 162.88\end{array}$ & $\begin{array}{c}1193.66 \\
\pm 16.81\end{array}$ & $\begin{array}{l}2310.67 \\
\pm 146.24\end{array}$ & $\begin{array}{c}5243.2 \\
\pm 106.64\end{array}$ & $\begin{array}{l}1404.41 \\
\pm 11.38\end{array}$ & n.d. & n.d. & n.d. & n.d. & $\begin{array}{c}9923.99 \\
\pm 390.9\end{array}$ & $\begin{array}{c}1428.49 \\
\pm 25.6\end{array}$ & $\begin{array}{l}4074.99 \\
\pm 232.15\end{array}$ & $\begin{array}{c}6628.3 \\
\pm 136.34\end{array}$ & n.d. & $\begin{array}{l}1441.67 \\
\pm 57.45\end{array}$ & $\begin{array}{l}1439.66 \\
\pm 57.45\end{array}$ & n.d. & n.d. & n.d. & n.d. & $\begin{array}{l}5086.39 \\
\pm 164.41\end{array}$ & $\begin{array}{l}7756.16 \\
\pm 65.18\end{array}$ & $\begin{array}{l}4041.3 \\
\pm 42.66\end{array}$ & $\begin{array}{l}587.45 \\
\pm 5.23\end{array}$ \\
\hline $\mathrm{Gd}$ & $\begin{array}{r}1342.66 \\
\pm 157.84 \\
\end{array}$ & $\begin{array}{c}1183.04 \\
\pm 2.91 \\
\end{array}$ & $\begin{array}{c}2409.34 \\
\pm 109.5 \\
\end{array}$ & $\begin{array}{c}5283.7 \\
\pm 126.88 \\
\end{array}$ & $\begin{array}{l}1375.12 \\
\pm 10.02 \\
\end{array}$ & n.d. & n.d. & n.d. & n.d. & $\begin{array}{l}10643.77 \\
\pm 587.79 \\
\end{array}$ & $\begin{array}{c}1460.09 \\
\pm 33.86 \\
\end{array}$ & $\begin{array}{r}3976.81 \\
\pm 238.12 \\
\end{array}$ & $\begin{array}{l}6550.85 \\
\pm 68.65 \\
\end{array}$ & n.d. & $\begin{array}{c}1469.82 \\
\pm 69.6\end{array}$ & $\begin{array}{c}1472.12 \\
\pm 69.6\end{array}$ & n.d. & n.d. & n.d. & n.d. & $\begin{array}{r}5418.7 \\
\pm 438.92 \\
\end{array}$ & $\begin{array}{c}8404.09 \\
\pm 65.13 \\
\end{array}$ & $\begin{array}{c}3976.29 \\
\pm 26.77\end{array}$ & $\begin{array}{r}585.48 \\
\pm 7.41 \\
\end{array}$ \\
\hline
\end{tabular}


Appendix A1. (continued)

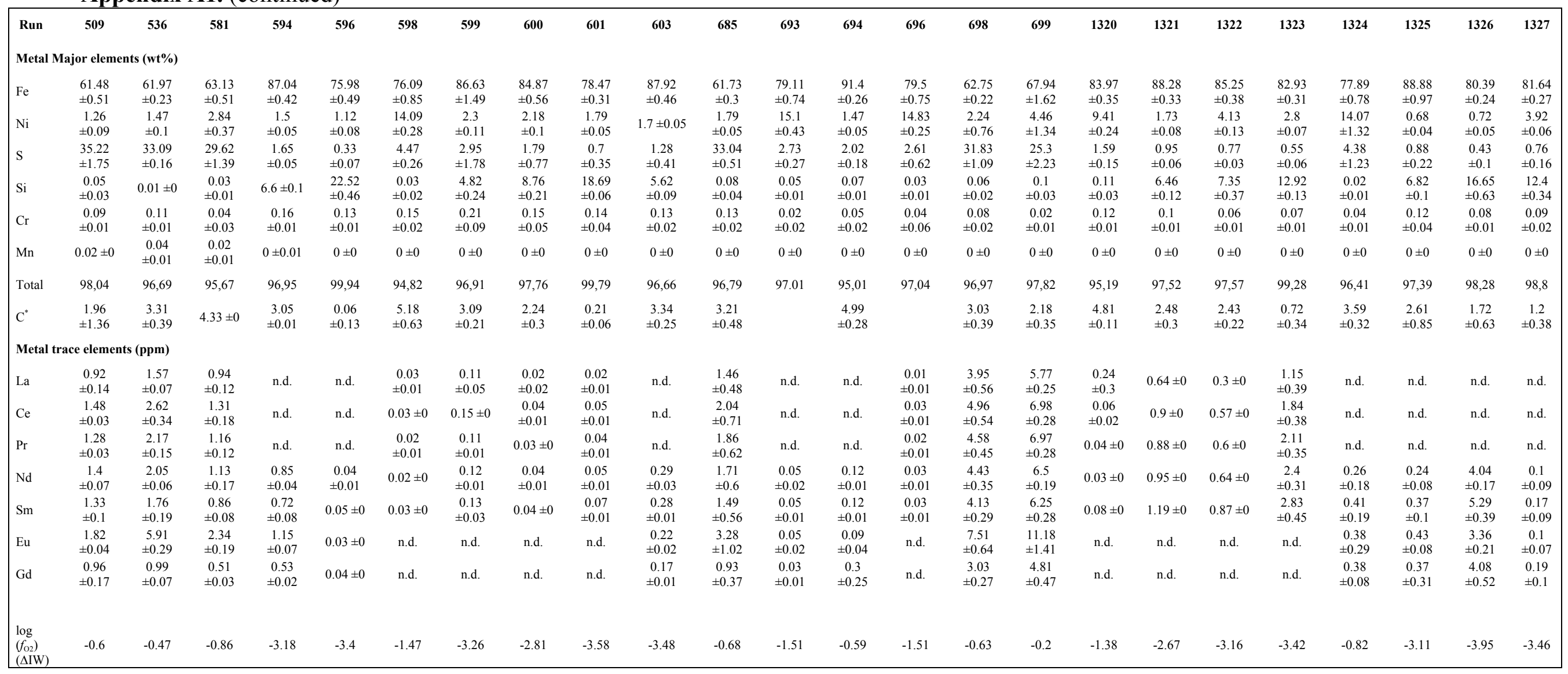

Table S1. Chemical analysis of the run products. Totals in silicate consider only major oxides, and only S-rich phase for the metallic phase when demixion in the Fe-S-Ni-C system occurs (see Appendix A2).

All the reported experiments were performed using the Hvittis based composition. Pressure uncertainties are estimated to be \pm 0.5 GPa of the reported values and temperature uncertainties are within $\pm 100 \mathrm{~K}$. Oxygen fugacities relative to Iron-Wüstite buffer assuming that $\gamma \mathrm{FeO}=1.5$, and $\gamma \mathrm{Fe}$ is calculated using the interaction parameters approach. Gr: Graphite; $\mathrm{MgO}$ : $\mathrm{MgO}$ single crystal.

${ }^{*}$ For samples embedded in graphite capsules, the maximum C contents in Fe-alloys is estimated from the deviation of the analyses totals from $100 \%$. 


\section{Appendix A2.}

\section{Role of graphite and MgO single-crystal capsules}

For experiments with graphite capsules, and for S-rich experiments, we observed the coexistence of two immiscible liquids in the run products for the experimental conditions investigated here (see Figure below). For instance, the experiment performed at $6 \pm 1 \mathrm{GPa}$ (run \#699) shows the coexistence of a S-rich liquid and a S-poor liquid. The chemical analyses of both phases are as following:

$\begin{array}{lr} & \text { S-rich phase } \\ \mathrm{Fe} & 67.94 \pm 1.62 \\ \mathrm{Ni} & 4.46 \pm 1.34 \\ \mathrm{~S} & 25.30 \pm 2.23 \\ \mathrm{Si} & 0.10 \pm 0.03 \\ \mathrm{Cr} & 0.02 \pm 0.01\end{array}$

Total $\quad 97.82 \pm 0.35$

Estimated

$\mathrm{C}(\mathrm{wt} \%) \quad 2.18 \pm 0.35$

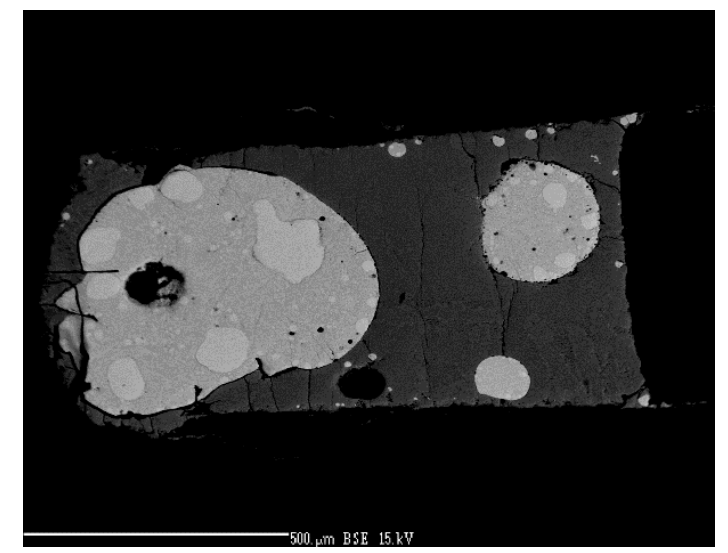

$$
\begin{array}{r}
\text { S-poor phase } \\
\hline 88.35 \pm 0.41 \\
3.26 \pm 0.18 \\
2.37 \pm 0.08 \\
0.06 \pm 0.02 \\
0.03 \pm 0.01
\end{array}
$$

$94.07 \pm 0.38$

Figure A2-1. Back-scattered electron image of a run-product recovered from $6 \pm 1 \mathrm{GPa}$ and $2439 \mathrm{~K}$ showing a coexistence in the metallic phase of S-rich and S-poor molten alloys.

The presence of carbon into the metallic phase is due to $\mathrm{C}$ diffusion from the graphite capsule into the sample. Observations of a demixion in the $\mathrm{Fe}-\mathrm{S}-\mathrm{Ni}-\mathrm{C}$ system are consistent with an immiscibility gap in the $\mathrm{Fe}-\mathrm{C}-\mathrm{S}$ system reported previously for pressures below $5.5 \mathrm{GPa}(e . g$. Corgne et al., 2008; Dasgupta et al., 2009).

By reporting the $\mathrm{C}$ content (for experiment with low $\mathrm{Si}$ content $<1 \mathrm{wt} \%$ ) versus the $\mathrm{S}$ content in the metallic phase for all the experiments in the present study (we estimated the $\mathrm{C}$ content as the deviation of the analyses totals from $100 \%$ ). We found that our semi-quantitative Canalyses are compatible with a decrease of the C-solubility with increasing S-content in the metallic liquid. 
Also $\mathrm{C}$ and $\mathrm{Si}$ contents of the metallic phase appear inversely correlated. These trends are consistent with previous experimental studies (Wang et al., 1991; Corgne et al., 2008; Dasgupta and Walker, 2008; Mann et al., 2009) and thermodynamic models at 1 bar (Bouchard and Bale, 1995).
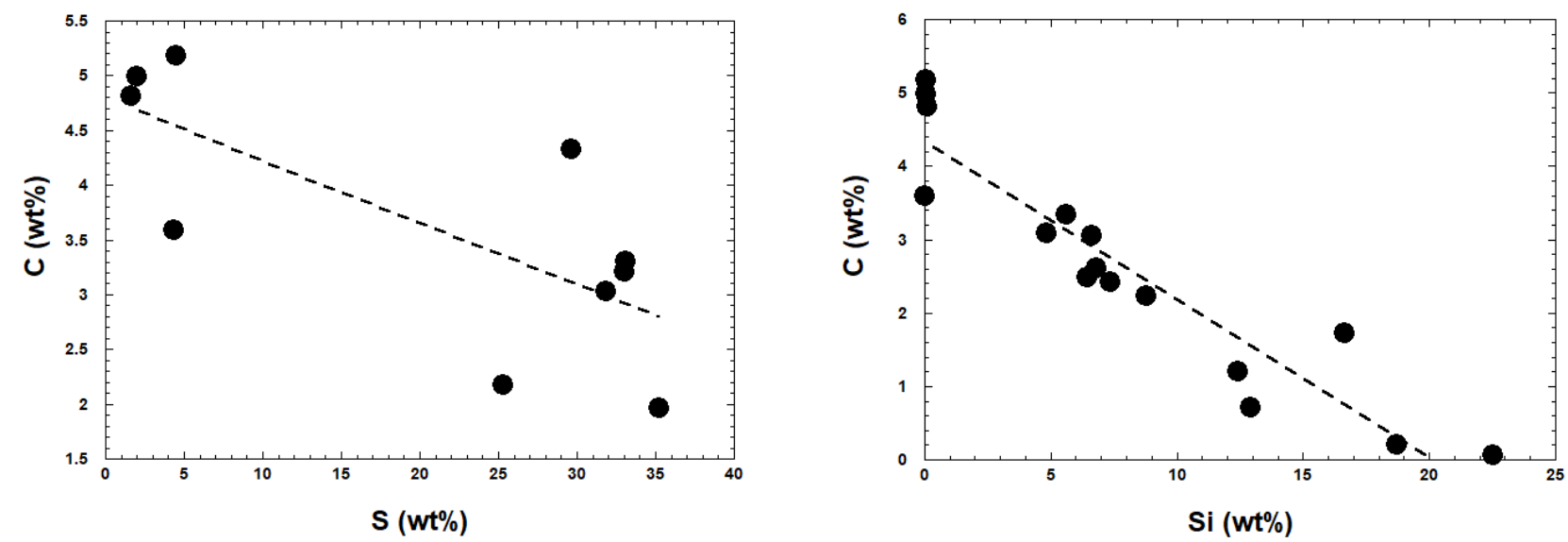

Figure A2-2. C (wt \%) vs $\mathrm{S}(\mathrm{wt} \%)$ and $\mathrm{C}(\mathrm{wt} \%)$ vs $\mathrm{Si}(\mathrm{wt} \%)$ for run-products with low $\mathrm{Si}$ content, and with low $\mathrm{S}$ content, respectively.

\section{Low totals for the run-products with $\mathrm{MgO}$ single-crystal capsules}

For two experiments with $\mathrm{MgO}$ capsules, we performed more than 20 chemical analyses and the Total in average is $97.33 \pm 0.25$. As reported in the back-scattered electron image below this is related to the state of the surface of the run-product that shows high level of porosity.

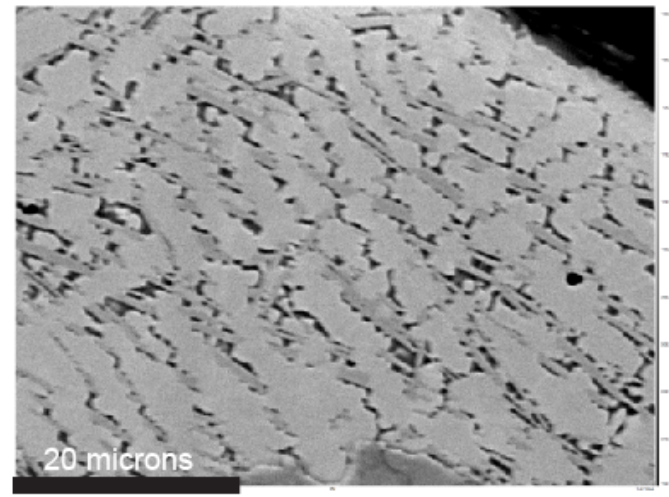

Figure A2-3. Back-scattered electron image of the metallic phase for a run-product recovered from $14 \pm 1 \mathrm{GPa}, 2560 \mathrm{~K}$, and using $\mathrm{MgO}$ as capsule. 
Appendix B. Effect of the nature of the capsule $(\mathrm{C}$ or $\mathrm{MgO})$ on $\mathrm{Sm}$ and $\mathrm{Nd}$ partition coefficients in our experiements. The experiments were performed in similar conditions (from 2450 to $2560 \mathrm{~K}$, at $\sim \mathrm{IW}-1.5$ in sulphur free environment), with the exception of pressure conditions. Error bars display 1 sigma uncertainties, showing no significant impact of the nature of the capsule or pressure on the resulting partition coefficients.
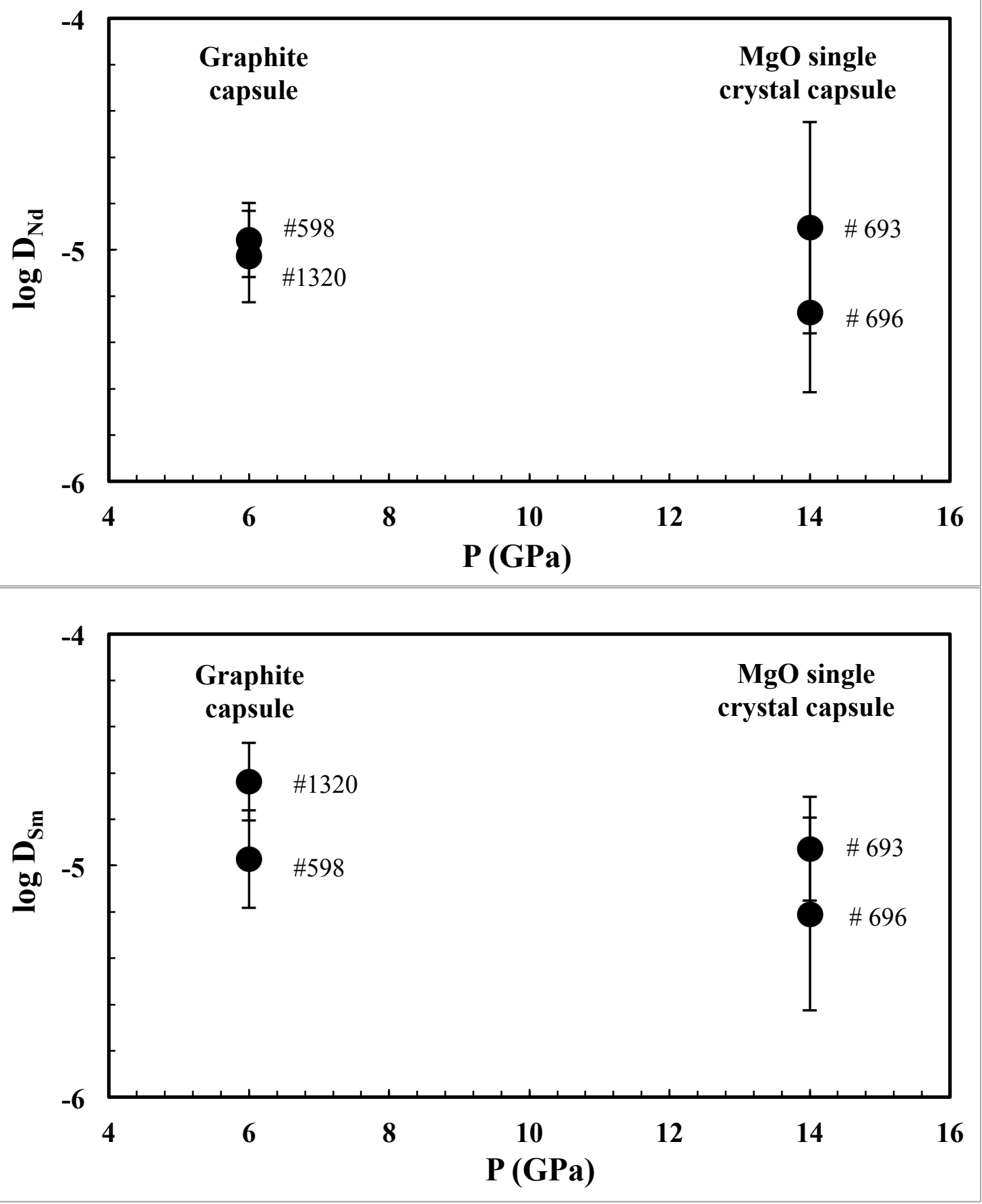
Appendix C. Compilation of experimental data

\begin{tabular}{|c|c|c|c|c|c|c|c|c|c|c|c|c|c|}
\hline Run & Capsule & $P(G P a)$ & $T(K)$ & $\begin{array}{c}\log f O_{2} \\
(\Delta I W)\end{array}$ & $N B O / T$ & $\begin{array}{c}X_{S \text { metal }} \\
(w t \%)\end{array}$ & $D_{L a}$ & $D_{C e}$ & $D_{P r}$ & $D_{N d}$ & $D_{S m}$ & $D_{E u}$ & $D_{G d}$ \\
\hline \multicolumn{14}{|c|}{ Bouhifd et al., 2015} \\
\hline 969 & $\mathrm{Gr}$ & 4 & 2128 & -1.43 & 3.61 & 0.00 & & & & $4.13 \times 10^{-5}$ & $4.43 \times 10^{-5}$ & & \\
\hline 975 & $\mathrm{Gr}$ & 4 & 2073 & -1.56 & 2.30 & 0.00 & & & & $5.05 \times 10^{-5}$ & $5.38 \times 10^{-5}$ & & \\
\hline 1026 & $\mathrm{Gr}$ & 5 & 2273 & -0.82 & 2.29 & 23.79 & & & & $1.08 \times 10^{-3}$ & $1.12 \times 10^{-3}$ & & \\
\hline 1027 & Gr & 5 & 2273 & -4.42 & 2.30 & 0.00 & & & & $1.60 \times 10^{-3}$ & $2.06 \times 10^{-3}$ & & \\
\hline 986 & $\mathrm{MgO}$ & 6 & 2173 & -1.64 & 2.08 & 0.00 & & & & $5.12 \times 10^{-5}$ & $6.14 \times 10^{-5}$ & & \\
\hline 1021 & $\mathrm{MgO}$ & 6 & 2173 & -1.44 & 2.35 & 21.53 & & & & $2.69 \times 10^{-4}$ & $3.75 \times 10^{-4}$ & & \\
\hline 1028 & $\mathrm{MgO}$ & 8 & 2373 & -1.45 & 2.16 & 19.10 & & & & $3.00 \times 10^{-4}$ & $2.75 \times 10^{-4}$ & & \\
\hline 1029 & $\mathrm{MgO}$ & 8 & 2373 & -4.67 & 2.14 & 0.00 & & & & $4.79 \times 10^{-3}$ & $5.44 \times 10^{-3}$ & & \\
\hline 1082 & $\mathrm{Gr}$ & 5 & 2023 & -4.60 & 0.52 & 0.00 & & & & $2.52 \times 10^{-2}$ & $3.01 \times 10^{-2}$ & & \\
\hline 1137 & $\mathrm{Gr}$ & 5 & 1973 & 0.90 & 1.73 & 35.31 & & & & $1.18 \times 10^{-3}$ & $7.73 \times 10^{-4}$ & & \\
\hline \multicolumn{14}{|c|}{ Wohlers and Wood., 2017} \\
\hline 701 & $\mathrm{Gr}$ & 1.5 & 2373 & -0.78 & 0.80 & 28.94 & $1.06 \times 10^{-2}$ & & & $1.10 \times 10^{-2}$ & $9.92 \times 10^{-3}$ & $1.87 \times 10^{-2}$ & \\
\hline 700 & Gr & 1.5 & 2373 & -3.73 & 0.24 & 34.50 & $3.94 \times 10^{-1}$ & $5.00 \times 10^{-1}$ & & $4.81 \times 10^{-1}$ & $4.75 \times 10^{-1}$ & $2.19 \times 10^{-1}$ & \\
\hline 699 & $\mathrm{Gr}$ & 1.5 & 2373 & -3.89 & 0.43 & 35.49 & $2.02 \times 10^{-1}$ & $1.43 \times 10^{-1}$ & & $2.35 \times 10^{-1}$ & $2.45 \times 10^{-1}$ & $2.29 \times 10^{-1}$ & \\
\hline 697 & $\mathrm{Gr}$ & 1.5 & 2373 & -3.95 & 0.25 & 35.73 & $3.28 \times 10^{-1}$ & $5.00 \times 10^{-1}$ & & $3.80 \times 10^{-1}$ & $3.78 \mathrm{E} \times 10^{-1}$ & $2.17 \times 10^{-1}$ & \\
\hline \multicolumn{14}{|c|}{ Ingrao et al., 2019} \\
\hline 1266 & & $8.50 \mathrm{E}-06$ & 1573 & -4.10 & & 36.88 & $1.70 \times 10^{-2}$ & $2.40 \times 10^{-2}$ & $3.00 \times 10^{-2}$ & $2.80 \times 10^{-2}$ & $4.50 \times 10^{-2}$ & $9.00 \times 10^{-2}$ & $2.40 \times 10^{-2}$ \\
\hline 1282 & & $7.00 \mathrm{E}-08$ & 1573 & -4.50 & & 36.56 & $3.40 \times 10^{-2}$ & $3.20 \times 10^{-2}$ & $4.30 \times 10^{-2}$ & $3.10 \times 10^{-2}$ & $4.10 \times 10^{-2}$ & $1.22 \times 10^{-1}$ & $2.00 \times 10^{-2}$ \\
\hline 1207 & & $9.00 \mathrm{E}-07$ & 1673 & -4.80 & & 38.23 & $3.86 \times 10^{-1}$ & $4.81 \times 10^{-1}$ & $4.25 \times 10^{-1}$ & $3.99 \times 10^{-1}$ & $3.27 \times 10^{-1}$ & $6.58 \times 10^{-1}$ & $1.52 \times 10^{-1}$ \\
\hline 1239 & & $8.50 \mathrm{E}-07$ & 1673 & -4.80 & & 36.48 & $5.50 \times 10^{-2}$ & $5.70 \times 10^{-2}$ & $4.80 \times 10^{-2}$ & $5.30 \times 10^{-2}$ & $5.10 \times 10^{-2}$ & $7.40 \times 10^{-2}$ & $3.00 \times 10^{-2}$ \\
\hline 1284 & & $7.00 \mathrm{E}-08$ & 1673 & -5.80 & & 36.66 & $2.40 \times 10^{-2}$ & $2.80 \times 10^{-2}$ & $2.60 \times 10^{-2}$ & $2.40 \times 10^{-2}$ & $1.90 \times 10^{-2}$ & $2.70 \times 10^{-2}$ & $9.00 \times 10^{-3}$ \\
\hline 1252 & & $1.00 \mathrm{E}-06$ & 1673 & -5.80 & & 36.56 & $2.72 \times 10^{-1}$ & $3.68 \times 10^{-1}$ & $4.06 \times 10^{-1}$ & $3.34 \times 10^{-1}$ & $2.96 \times 10^{-1}$ & $5.98 \times 10^{-1}$ & $1.40 \times 10^{-1}$ \\
\hline
\end{tabular}


Appendix C. (continued)

\begin{tabular}{|c|c|c|c|c|c|c|c|c|c|c|c|c|c|}
\hline Run & Capsule & $P(G p a)$ & $T(K)$ & $\begin{array}{c}\log f O_{2} \\
(\Delta I W)\end{array}$ & $N B O / T$ & $\begin{array}{c}X_{S \text { metal }} \\
(w t \%) \\
\end{array}$ & $D_{L a}$ & $D_{C e}$ & $D_{P r}$ & $D_{N d}$ & $D_{S m}$ & $D_{E u}$ & $D_{G d}$ \\
\hline \multicolumn{14}{|c|}{ Lodders (1996) } \\
\hline EQ6 & $\mathrm{Gr}$ & & 1473 & 2.36 & & 43.7 & $1.00 \times 10^{-2}$ & & $1.00 \times 10^{-2}$ & & $9.00 \times 10^{-3}$ & $6.50 \times 10^{-2}$ & $5.00 \times 10^{-3}$ \\
\hline EQ1 & $\mathrm{Gr}$ & & 1483 & 2.46 & & 43.6 & $9.00 \times 10^{-3}$ & & $9.00 \times 10^{-3}$ & $7.50 \times 10^{-3}$ & $5.50 \times 10^{-3}$ & $4.40 \times 10^{-2}$ & $5.80 \times 10^{-3}$ \\
\hline VQ1 & $\mathrm{Gr}$ & & 1473 & 2.26 & & 43.56 & $1.50 \times 10^{-2}$ & & $1.60 \times 10^{-2}$ & $1.70 \times 10^{-2}$ & $1.40 \times 10^{-2}$ & $6.60 \times 10^{-2}$ & $1.40 \times 10^{-2}$ \\
\hline VQ2 & $\mathrm{Gr}$ & & 1473 & 2.36 & & 39.5 & $5.60 \times 10^{-3}$ & & $6.00 \times 10^{-3}$ & $8.00 \times 10^{-3}$ & $4.60 \times 10^{-3}$ & $3.90 \times 10^{-2}$ & $3.00 \times 10^{-3}$ \\
\hline VQ4 & $\mathrm{Gr}$ & & 1473 & 0.26 & & 36 & $4.10 \times 10^{-3}$ & & $3.50 \times 10^{-3}$ & & $3.70 \times 10^{-3}$ & $6.00 \times 10^{-3}$ & $2.80 \times 10^{-3}$ \\
\hline VQ3 & $\mathrm{Gr}$ & & 1473 & -1.44 & & 33.6 & $1.30 \times 10^{-3}$ & & $1.20 \times 10^{-3}$ & & $1.30 \times 10^{-3}$ & $7.00 \times 10^{-3}$ & \\
\hline EQ9 & $\mathrm{Gr}$ & & 1473 & -2.74 & & 37.65 & $2.90 \times 10^{-1}$ & & $3.30 \times 10^{-1}$ & $2.50 \times 10^{-1}$ & $1.70 \times 10^{-1}$ & $8.50 \times 10^{-1}$ & $8.10 \times 10^{-2}$ \\
\hline EQ10 & $\mathrm{Gr}$ & & 1473 & -2.84 & & 14.71 & $4.80 \times 10^{-1}$ & & $5.10 \times 10^{-1}$ & $3.80 \times 10^{-1}$ & $2.00 \times 10^{-1}$ & 1.08 & $1.40 \times 10^{-1}$ \\
\hline EQ4 & $\mathrm{Gr}$ & & 1473 & 0 & & 33.9 & $1.40 \times 10^{-3}$ & & $1.00 \times 10^{-3}$ & & $7.00 \times 10^{-4}$ & $3.50 \times 10^{-3}$ & \\
\hline EQ3 & $\mathrm{Gr}$ & & 1473 & -0.34 & & 35 & $6.00 \times 10^{-4}$ & & & & & $3.00 \times 10^{-3}$ & \\
\hline QR1 & $\mathrm{Gr}$ & & 1473 & 1.76 & & 44.45 & $3.10 \times 10^{-2}$ & & & & $1.60 \times 10^{-2}$ & $1.15 \times 10^{-1}$ & \\
\hline QR2 & $\mathrm{Gr}$ & & 1473 & 2.16 & & 40.42 & $3.80 \times 10^{-2}$ & & & & $2.50 \times 10^{-2}$ & $1.64 \times 10^{-1}$ & \\
\hline
\end{tabular}

Table S2. Compilation of the experimental data used to derive the coefficients of equation (4) for all studied REE. The uncertainties on the reported data can be found in the original papers. 
Appendix D. Effect of experimental conditions on REE metal-silicate partition coefficients.

D.1 Evolution of $\mathrm{D}_{\mathrm{REE}}$ with $\log f_{\mathrm{O}_{2}}$. Presented results are from this study (Appendix A) and from literature (Apprendix B). Data are corrected from the effect of metalic sulphur, using the parametrization presented in equation 6 and Table 2 .
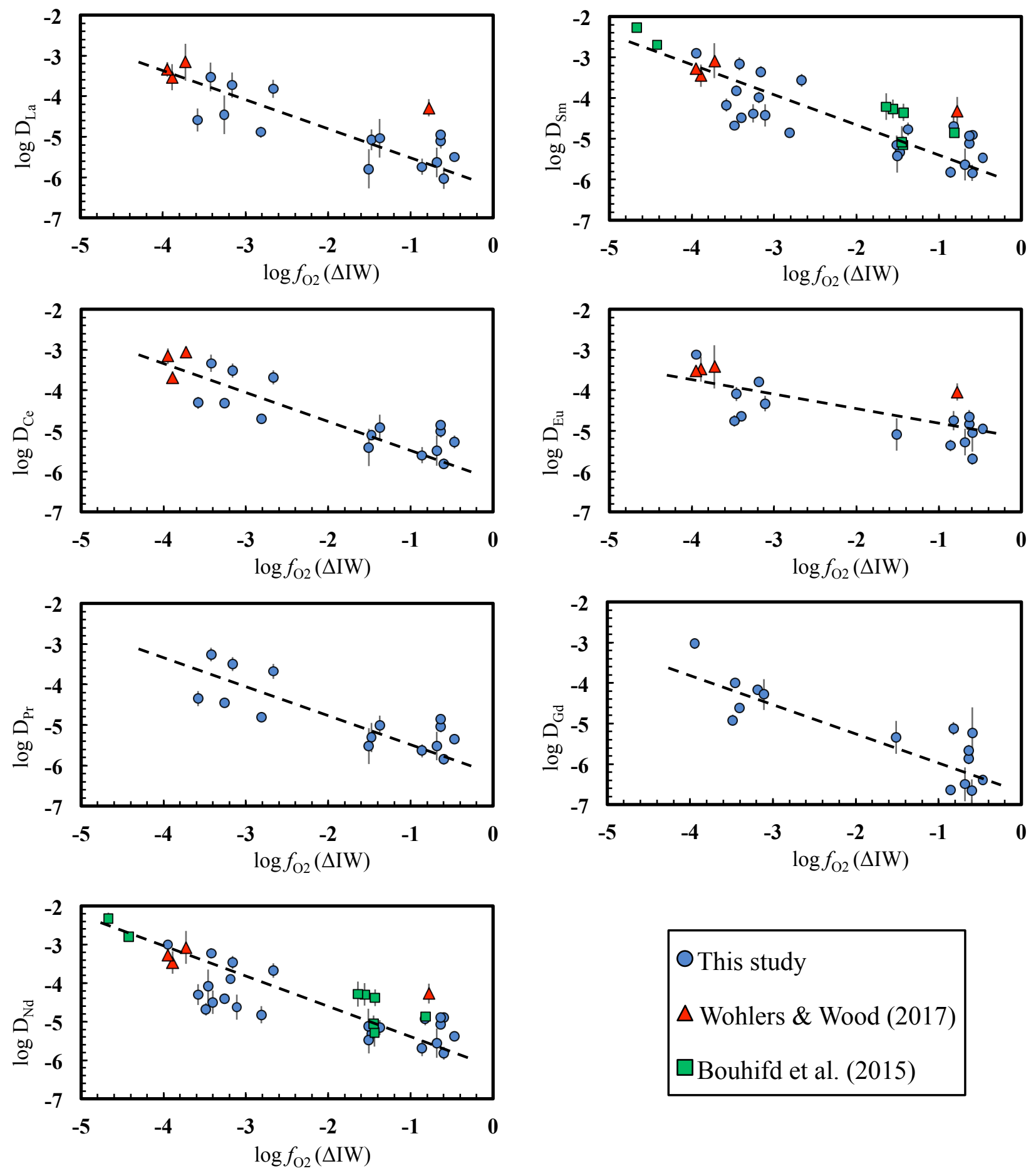

This study

$\Delta$ Wohlers \& Wood (2017)

$\square$ Bouhifd et al. (2015) 
Appendix D.2 Evolution of $\mathrm{D}_{\mathrm{REE}}$ with the $\mathrm{S}$ concentration in the metal. Presented results are from this study (Appendix A) and from literature (Apprendix B). Data are corrected for the effect of oxygen fugacity, using the parametrization presented in equation 6 and Table 2.
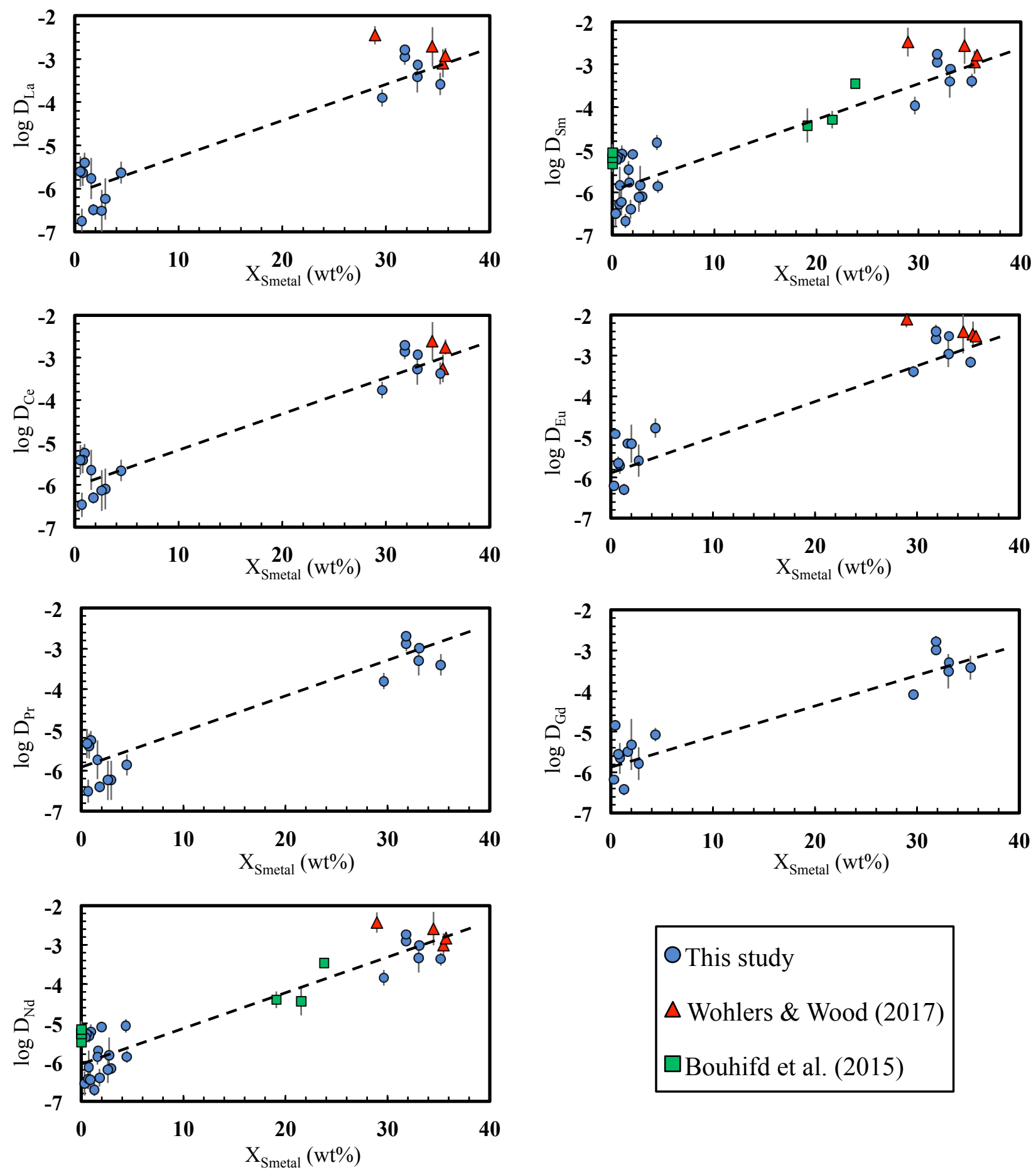

OThis study

$\Delta$ Wohlers \& Wood (2017)

$\square$ Bouhifd et al. (2015) 


\section{Appendix D3. Effect of temperature on metal - silicate partitioning of REE}

In the following, we will use $\mathrm{Nd}$ as an example to determine the effect of temperature on metal-silicate partitioning of the REE.

The metal - silicate partitioning of $\mathrm{Nd}$ is shown relative to that of Fe in terms of an exchange reaction:

$\mathrm{Nd}_{2} \mathrm{O}_{3 \text { (silicate) }}+3 \mathrm{Fe}_{(\text {metal })}=2 \mathrm{Nd}_{(\text {metal })}+3 \mathrm{FeO}_{\text {(silicate) }}$

The free energy of the reaction $\Delta \mathrm{G}_{\text {reaction }}=\Delta \mathrm{H}_{\text {reaction }}-\mathrm{T} \Delta \mathrm{S}_{\text {reaction }}$

where $\Delta \mathrm{H}_{\text {reaction }}$ and $\Delta \mathrm{S}_{\text {reaction }}$ are the enthalpy and the entropy of the reaction, respectively.

$\Delta \mathrm{H}_{\text {reaction }}=3 \mathrm{H}_{\text {formation }}(\mathrm{FeO})-\mathrm{H}_{\text {formation }}\left(\mathrm{Nd}_{2} \mathrm{O}_{3}\right)$

Using tabulated values of $\mathrm{H}_{\text {formation }}(\mathrm{FeO})$ from Robie and Hemingway (1995); and those of Gschneidner et al. (1973) and Barin et al. (1989) for $\mathrm{Nd}_{2} \mathrm{O}_{3}$, a value of approximately 1000 $\mathrm{kJ} / \mathrm{mol}$ is obtained for $\Delta \mathrm{H}_{\text {reaction }}$ at $2000 \mathrm{~K}$.

In addition, $\Delta \mathrm{S}_{\text {reaction }}=2 \mathrm{~S}(\mathrm{Nd})+3 \mathrm{~S}(\mathrm{FeO})-\mathrm{S}\left(\mathrm{Nd}_{2} \mathrm{O}_{3}\right)-3 \mathrm{~S}(\mathrm{Fe})$.

Using tabulated values of Barin et al. (1989) for Nd, of Gschneidner et al. (1973) and Barin et al. (1989) for $\mathrm{Nd}_{2} \mathrm{O}_{3}$, and of Robie and Hemingway (1995) for $\mathrm{Fe}$ and $\mathrm{FeO}$, a value of approximately $100 \mathrm{~J} / \mathrm{mol} \mathrm{K}$ is obtained for $\Delta \mathrm{S}_{\text {reaction }}$ at $2000 \mathrm{~K}$.

Therefore, the term $\mathrm{T} \Delta \mathrm{S}_{\text {reaction }}$ is about one order of magnitude lower than the term $\Delta \mathrm{H}_{\text {reaction. }}$. Varying the temperature in the likely range during core formation (2500 to $3500 \mathrm{~K})$, will result in a small change on $\Delta \mathrm{G}_{\text {reaction. }}$. From this, and considering that the effect of temperature on $\Delta \mathrm{H}_{\text {reaction }}$ is negligible, we conclude that temperature should not affect metal-silicate partitioning of $\mathrm{Nd}$, and, by extension, all $\mathrm{REE}$. 
Appendix E. Accretion model.

We present here models of planetary accretion focusing on the evolution of the REE (La to Gd) content of the different reservoirs (core, bulk silicate Earth) during metal-silicate differentiation.

At each step of accretion $\left(1 \% \mathrm{M}_{\mathrm{E}}\right)$, the impactor's metal and silicate equilibrate within the proto-mantle, which represents $68 \%$ of planet's mass throughout the entire accretion. Equilibration pressure is set at a pressure of $50 \%$ of the core-mantle boundary at each step. This fraction is derived from previous studies on the partitioning of siderophile elements sensitive to pressure (e.g. Boujibar et al., 2014; Fischer et al., 2015), leading to a final equilibration pressure set at $60 \mathrm{GPa}$ (Siebert et al., 2012). Temperature is fixed at the liquidus of chondritic melts given in Andrault et al., (2011), evolving from $1900 \mathrm{~K}$ when the protoEarth is at $1 \%$ of its final mass up to $3500 \mathrm{~K}$ in the final stage of accretion. The oxygen fugacity is constrained to the $f_{\mathrm{O}_{2}}$ paths defined in Clesi et al., (2016), into a range going from IW-5 to IW-2. All scenarios studied here reproduced within error, the Earth primitive mantle $f_{\mathrm{O}_{2}} \approx \Delta \mathrm{IW}-2.3$.

Each increment of the model represent the growth of the proto-Earth of $1 \%$ of its final mass, by the arrival of impactors already differentiated into silicate mantles and metallic cores (Taylor and Norman, 1990). The initial chemical compositions of impactors are those measured on various types of chondrites, depending of the studied scenarios chondrites mixtures (Wasson and Kallemeyn, 1988; see below for REE). The compositions of both metal and silicate reservoirs are calculated at $1 \mathrm{GPa}$ and $2000 \mathrm{~K}$ for every element studied here, using their respective partition coefficients. The metal silicate equilibration takes place at $f_{\mathrm{O}_{2}}$ conditions coherent with the type of chondrites attributed to each accretion step, ranging from $\sim$ IW -4 to IW (Brett and Sato, 1984). In any way, the silicate reservoir of the impactor 
contains the near total of all REE because the differentiation leads to a maximum of a few ppb of the studied REE in the metallic phase.

Partitioning is determined using our parameterizations from Table 2. Following the approach of Deguen et al. (2014), we take into account the effect of partial metal-silicate equilibration on element partitioning, which is mainly effective during the final $40 \%$ of Earth's accretion. We apply here the method detailed in Rubie et al. (2011) in order to reproduce the metalsilicate partial equilibration by modeling an exponential decrease of the equilibration rates during the last stage of accretion (see equation 4 of Rubie et al., 2011). We consider that the equilibration between the proto-Earth's mantle and the metal of the impactor becomes less efficient as the accretion progresses (e.g. Deguen et al., 2014; Rubie et al., 2015). For the last giant impact that formed the Moon $\left(\mathrm{M}_{\mathrm{I}}=0.1 \mathrm{M}_{\mathrm{E}}\right)$, the impactor's core merges almost completely with the Earth's proto-core, with less than $5 \%$ of its mass equilibrating with the silicate mantle. Due to the lithophile behavior of REE, the impact of equilibration on our results is very limited, in agreement with Rudge et al., (2010). At each step of accretion, the content of the metallic core in $\mathrm{Ni}, \mathrm{O}$ and $\mathrm{Si}$ is defined using the parametrisations of Fischer et al. (2015). The $\mathrm{C}$ content of the core remains constant at $0.2 \mathrm{wt} \%$ during accretion (Wood et al., 2006), and a late addition of sulfur-rich material increases the $\mathrm{S}$ content of the core to 2 wt $\%$ to fit geophysical, geochemical, and experimental estimates (e.g., Allègre et al., 1995; Boujibar et al., 2014; Dreibus and Palme, 1996; Palme and O’Neill, 2003, Suer et al., 2017). Variations of the $\mathrm{O}$ and $\mathrm{Si}$ contents in the metal are related to the proportion of reduced and oxidized building blocks, which influence the $f_{\mathrm{O}_{2}}$ path. In models that consider a fully accreted Earth built from a major proportion $(80 \%)$ of reduced materials, the Earth's core contains $0.2 \mathrm{wt} \% \mathrm{C}, 2 \mathrm{wt} \% \mathrm{~S}, 6.75 \pm 0.75 \mathrm{wt} \% \mathrm{Si}$, and $2.8 \pm 0.7 \mathrm{wt} \% \mathrm{O}$. However the incorporation of these light elements into the core lead to a negligible enrichment (no more than $1.3 \%$ ) of the silicate reservoir in REE. 
In order to use the most precise and up-to-date REE concentrations for the various types of chondrites proposed as building blocks for the Earth, we compiled data from the most recent publications. The lowest concentrations in REE among the different groups of chondrites are measured in CI and enstatite chondrites whereas the most enriched are those of the CV group (factor 2). For the EL subgroup, data on EL3 from Barrat et al. (2014) are considered. Most EL samples belong to the EL6 subgroup and show depletion in light REE relative to heavy REE due to melting and thermal metamorphism events (Barrat et al., 2014; Boyet et al., 2018; Rubin et al., 2009). Concentrations used in this model are presented in the table below (Table $\mathrm{S} 3$ ), along with the enrichment factor $f_{\text {dry }}$ which is applied to the REE concentrations in order to take volatile depletion observed on Earth compared to chondrites into account (for details see text).

\begin{tabular}{|c|c|c|c|c|c|c|c|c|c|}
\hline & La & $\mathrm{Ce}$ & $\operatorname{Pr}$ & Nd & Sm & Eu & Gd & $f_{\text {dry }}$ & references \\
\hline EH & $222 \pm 17$ & $575 \pm 35$ & $86 \pm 5$ & $433 \pm 21$ & $138 \pm 6$ & $52 \pm 2$ & $194 \pm 12$ & 1.59 & $\begin{array}{c}\text { Barrat et al., } 2014 \\
\text { Dauphas and Pourmand } 2015\end{array}$ \\
\hline EL & $250 \pm 53$ & $650 \pm 120$ & $100 \pm 18$ & $509 \pm 87$ & $166 \pm 31$ & $59 \pm 7$ & $235 \pm 33$ & 1.61 & Boyet et al.,2018 \\
\hline CI & $248 \pm 26$ & $637 \pm 58$ & $98 \pm 42$ & $496 \pm 35$ & $161 \pm 10$ & $61 \pm 4$ & $221 \pm 16$ & 2.39 & $\begin{array}{c}\text { Barrat et al., } 2012 \\
\text { Braukmuller et al., } 2018 \\
\text { Pourmand and Dauphas., } 2012 \\
\text { Dauphas and Pourmand., } 2015\end{array}$ \\
\hline $\mathbf{C V}$ & $475 \pm 45$ & $1194 \pm 113$ & $188 \pm 8$ & $963 \pm 72$ & $309 \pm 25$ & $108 \pm 6$ & $411 \pm 34$ & 1.69 & \\
\hline CO & $363 \pm 104$ & $949 \pm 242$ & $151 \pm 27$ & $784 \pm 105$ & $255 \pm 29$ & $96 \pm 12$ & $362 \pm 9$ & 1.67 & $\begin{array}{c}\text { Braukmuller et al., } 2018 \\
\text { Dauphas and Pourmand., } 2015\end{array}$ \\
\hline CM & $294 \pm 33$ & $772 \pm 79$ & $122 \pm 12$ & $620 \pm 61$ & $203 \pm 19$ & $77 \pm 7$ & $315 \pm 51$ & 2.02 & \\
\hline $\mathbf{H}$ & $397 \pm 146$ & $957 \pm 229$ & $142 \pm 32$ & $700 \pm 135$ & $216 \pm 32$ & $81 \pm 6$ & $289 \pm 37$ & 1.62 & \\
\hline $\mathbf{L}$ & $324 \pm 53$ & $908 \pm 218$ & $135 \pm 31$ & $683 \pm 155$ & $217 \pm 47$ & $83 \pm 9$ & $290 \pm 56$ & 1.69 & Dauphas and Pourmand., 2015 \\
\hline $\mathbf{L L}$ & $434 \pm 181$ & $1134 \pm 476$ & $168 \pm 69$ & $844 \pm 338$ & $265 \pm 102$ & $91 \pm 9$ & $352 \pm 130$ & 1.77 & \\
\hline
\end{tabular}

Table S3. REE concentrations (in ppb) for chondrite groups used in our calculation, taken from the most recent published trace element measurements on chondrites. $f_{\text {dry }}$ corresponds to the enrichment factor applied to concentrations of REE presented here in order to take the volatile depletion observed on Earth relative to chondrites into account. 


\section{Appendix References}

Andrault, D., Bolfan-Casanova, N., Nigro, G.L., Bouhifd, M.A., Garbarino, G., and Mezouar, M. (2011). Solidus and liquidus profiles of chondritic mantle: Implication for melting of the Earth across its history. Earth and Planetary Science Letters 304, 251-259.

Barin, I., Sauert, F., Schultze-Rhonhof, E., Sheng, W.S. (1989) Thermochemical Data of Pure Substances, Part I and Part II, CH Verlagsgesellschaft, Weinheim, Germany. 1739 pp.

Barrat, J.A., Zanda, B., Jambon, A., and Bollinger, C. (2014). The lithophile trace elements in enstatite chondrites. Geochimica et Cosmochimica Acta 128, 71-94.

Bouchard, D. and Bale, C.W. (1995) Simultaneous optimization of thermochemical data for liquid iron alloys containing C, N, Ti, Si, Mn, S, and P. Metall. Mater. Trans. B 26, $467-$ 484.

Boujibar, A., Andrault, D., Bouhifd, M.A., Bolfan-Casanova, N., Devidal, J.-L., and Trcera, N. (2014). Metal-silicate partitioning of sulphur, new experimental and thermodynamic constraints on planetary accretion. Earth and Planetary Science Letters 391, 42-54.

Boyet, M., Bouvier, A., Frossard, P., Hammouda, T., Garçon, M., and Gannoun, A. (2018). Enstatite chondrites EL3 as building blocks for the Earth: The debate over the $146 \mathrm{Sm}-$ $142 \mathrm{Nd}$ systematics. Earth and Planetary Science Letters 488, 68-78.

Brett R. \& Sato M. (1984) Intrinsic oxygen fugacity measurements on seven chondrites, a pallasite, and a tektite and the redox state of meteorite parent bodies. Geochimica et Cosmochimica Acta 48, 111-120.

Clesi, V., Bouhifd, M.A., Bolfan-Casanova, N., Manthilake, G., Fabbrizio, A., and Andrault, D. (2016). Effect of $\mathrm{H}_{2} \mathrm{O}$ on metal-silicate partitioning of $\mathrm{Ni}, \mathrm{Co}, \mathrm{V}, \mathrm{Cr}, \mathrm{Mn}$ and $\mathrm{Fe}$ : Implications for the oxidation state of the Earth and Mars. Geochimica et Cosmochimica Acta 192, 97-121.

Corgne, A., Wood, B.J. and Fei, Y. (2008) C- and S-rich molten alloy immiscibility and core formation of planetesimals. Geochim. Cosmochim. Acta 72, 2409-2416.

Dasgupta, R., Buono, A., Whelan, G. and Walker, D. (2009) High pressure melting relations in $\mathrm{Fe}-\mathrm{C}-\mathrm{S}$ systems: implications for formation, evolution, and structure of metallic cores in planetary bodies. Geochim. Cosmochim. Acta 73, 6678-6691.

Dasgupta, R. and Walker, D. (2008) Carbon solubility in core melts in a shallow magma ocean environment and distribution of carbon between the Earth's core and the mantle. Geochim. Cosmochim. Acta 72, 4627-4641.

Deguen, R., Landeau, M., and Olson, P. (2014). Turbulent metal-silicate mixing, fragmentation, and equilibration in magma oceans. Earth and Planetary Science Letters $391,274-287$.

Fischer, R.A., Nakajima, Y., Campbell, A.J., Frost, D.J., Harries, D., Langenhorst, F., Miyajima, N., Pollok, K., and Rubie, D.C. (2015). High pressure metal-silicate partitioning of Ni, Co, V, Cr, Si, and O. Geochimica et Cosmochimica Acta 167, 177194.

Gschneidner, K.A., Kippenhan, N.A., McMasters, O.D. (1973): Thermochemistry of the rare Earths. Rare-Earth Information Center, Institute for Atomic Research, Iowa State University, Ames, Iowa. 
Mann, U., Frost, D.J. and Rubie D.C. (2009) Evidence for high pressure core-mantle differentiation from the metal-silicate partitioning of lithophile and weakly-siderophile elements. Geochim. Cosmochim. Acta 73, 7360-7386.

Robie, R.A., Hemingway B.S. (1995): Thermodynamic properties of minerals and relied substances at $298.15 \mathrm{~K}$ and 1 bar $\left(10^{5}\right.$ Pascals $)$ pressure and at higher temperatures. U.S. Geological Survey Bulletin 2131.

Rubie, D.C., Frost ,D.J., Mann, U., Asahara, Y., Nimmo, F., Tsuno, K., Kegler, P., Holzheid, A. \& Palme, H. (2011) Heterogeneous accretion, composition and core-mantle differentiation of the Earth. Earth Planet. Sci. Lett. 301, 31-42.

Rubie, D.C., Jacobson, S.A., Morbidelli, A., O’Brien, D.P., Young, E.D., de Vries, J., Nimmo, F., Palme, H., and Frost, D.J. (2015). Accretion and differentiation of the terrestrial planets with implications for the compositions of early-formed Solar System bodies and accretion of water. Icarus $248,89-108$.

Rubin, A.E., Huber, H., and Wasson, J.T. (2009). Possible impact-induced refractorylithophile fractionations in EL chondrites. Geochimica et Cosmochimica Acta 73, 15231537.

Rudge, J.F., Kleine, T., and Bourdon, B. (2010). Broad bounds on Earth's accretion and core formation constrained by geochemical models. Nature Geoscience 3, 439-443.

Siebert, J., Badro, J., Antonangeli, D., and Ryerson, F.J. (2012). Metal-silicate partitioning of $\mathrm{Ni}$ and $\mathrm{Co}$ in a deep magma ocean. Earth and Planetary Science Letters 321-322, 189197.

Taylor, S., and Norman, M. (1990). Accretion of differentiated planetesimals to the Earth. Origin of the Earth 1, 29-43.

Suer, T.-A., Siebert, J., Remusat, L., Menguy, N., Fiquet, G., 2017. A sulfur-poor terrestrial core inferred from metal-silicate partitioning experiments. Earth Planet. Sci. Lett. 469, 84-97.

Wang, C., Hirama, J., Nagasaka, T. and Ban-Ya, S. (1991) Phase equilibria of liquid Fe-S-C ternary system. ISIJ International 31, 1292-1299.

Wasson, J.T., and Kallemeyn, G.W. (1988). Compositions of Chondrites. Philosophical Transactions of the Royal Society A: Mathematical, Physical and Engineering Sciences $325,535-544$.

Wohlers, A., and Wood, B.J. (2015). A Mercury-like component of early Earth yields uranium in the core and high mantle $142 \mathrm{Nd}$. Nature 520, 337-340. 